Portland State University

PDXScholar

$1-1-1979$

\title{
Seasonal variation in cytokinin activity and content in two species of dwarf mistletoes and their hosts
}

Peter J. Paquet

Portland State University

Follow this and additional works at: https://pdxscholar.library.pdx.edu/open_access_etds Let us know how access to this document benefits you.

\section{Recommended Citation}

Paquet, Peter J., "Seasonal variation in cytokinin activity and content in two species of dwarf mistletoes and their hosts" (1979). Dissertations and Theses. Paper 864.

https://doi.org/10.15760/etd.864

This Dissertation is brought to you for free and open access. It has been accepted for inclusion in Dissertations and Theses by an authorized administrator of PDXScholar. Please contact us if we can make this document more accessible: pdxscholar@pdx.edu. 
SEASONAL VARIATION IN CYTOKININ ACTIVITY AND CONTENT

IN TWO SPECIES OF DWARF MISTLETOES AND THEIR HOSTS

by

PETER J. PAQUET

A dissertation submitted in partial fulfillment of the requirements for the degree of

DOCTOR OF PHILOSOPHY

in

ENVIRONMENTAL SCIENCES AND RESOURCES - BIOLOGY

Portland State University

1979 
TO THE OFFICE OF GRADUATE STUDIES AND RESEARCH:

The members of the Committee approve the dissertation of

Peter J. Paquet presented March 7, 1979.

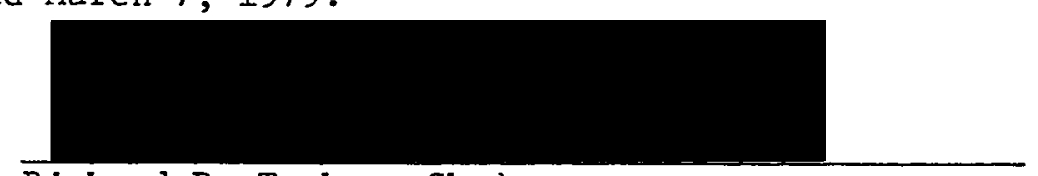

Richard D. Tocher, Chairman

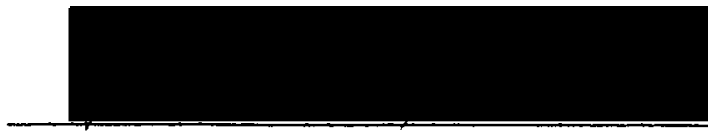

Robert 0 . Tinnin

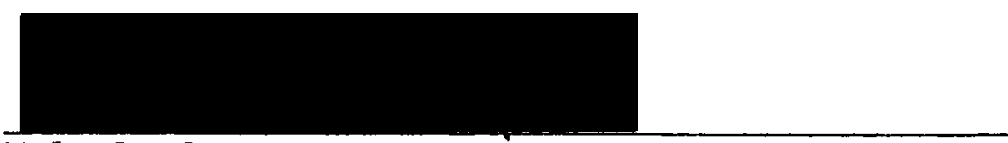

Malcolm S. Lea

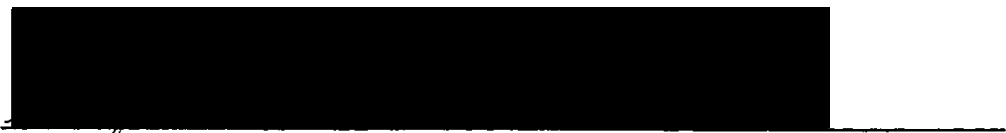

Alfreda S. Levinson

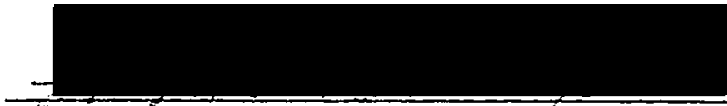

Raymond W. Sommerfeldt

APPROVED :

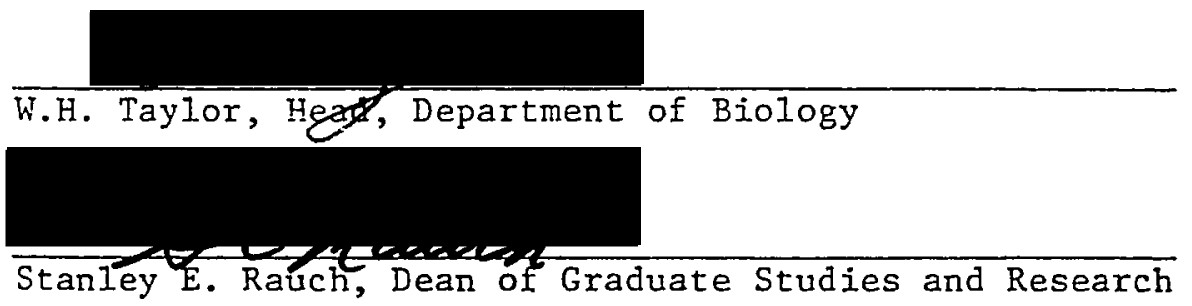


AN ABSTRACT OF THE DISSERTATION OF Peter J. Paquet for the Doctor of Philosophy in Environmental Sciences and Resources-Biology presented March 7, 1979.

Title: Seasonal Variation in Cytokinin Activity and Content in Two Species of Dwarf Mistletoes and Their Hosts. APPROVED BY MEMBERS OF THE DTSSERTATTON COMRTTTREF.
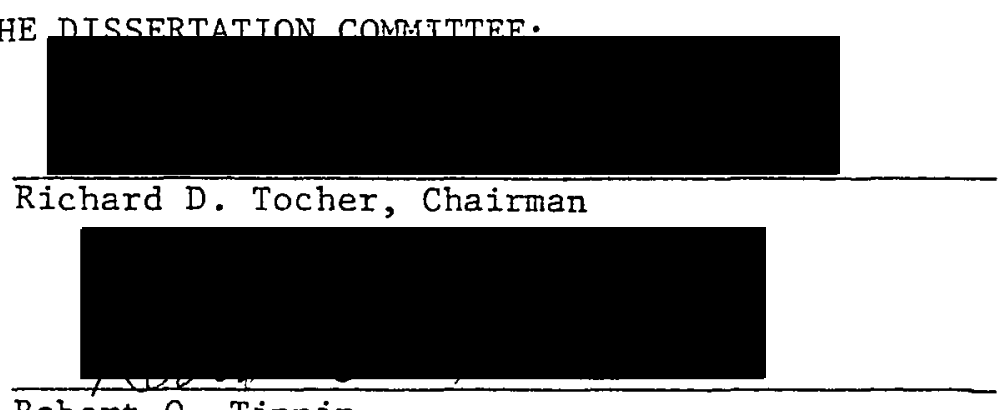
Robert 0 . Tinnin

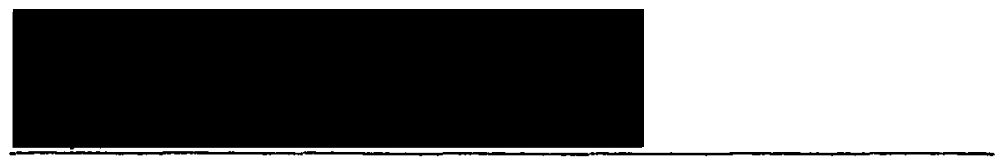
Malcolm Lea

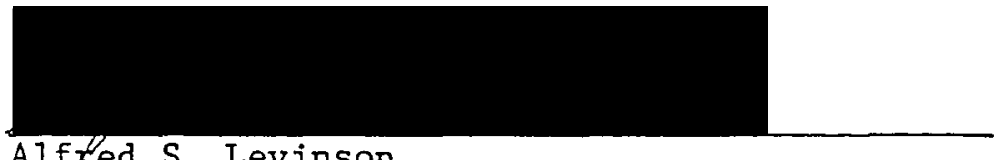
Alfzed S. Levinson

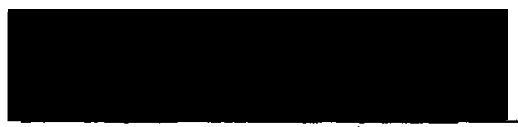

Raymond Somerfeldt

Cytokinin levels were determined by bioassay on a seasonal basis, for two species of dwarf mistletoes (Arceuthobium douglasii and Arceuthobium tsugense) and their respective hosts, Douglas-fir (pseudotsuga menziesii) and western hemlock (Isuga heterophylla). The highest cytokinin levels occurzed in early Spring for all of the samples studied. 
However, with the exception of the first growth segments of Douglas-fir, the levels of cytokinins detected were significantly greater in infected tissue and aerial shoots of the mistletoe than in the healthy tissue. Further studies were carried out on Spring and Winter samples to determine the kinds of cytokinins present. High performance thin layer chromatography and gas liquid chromatography results showed that zeatin riboside $(\mathrm{ZR})$ was the only detectable cytokinin in winter samples. . ZR was also detected in all Spring samples excepting the aerial shoots of A. douglasii. Two other cytokinins, zeatin and $N^{6}-\left(\Delta^{2}\right.$ isopentenyl $)$ adenosine (2iPA) were also detectable in Spring samples. Zeatin was present in aerial shoots from both dwarf mistletoes and in the infected fifth growth segments from Douglas-fir and in infected western hemlock tissue. Zeatin occurred in the healthy tissue only in first growth segments of Douglas-fir.

The 2iPA was detectable in the aerial shoots of the dwarf mistletoes, in the fifth growth segments of Douglas-fir, and in the infected tissue from western hemlock.

These results are discussed with particular reference to the role of cytokinins in the physiological interactions between the host and the parasite. 


\section{ACKNOWLEDGMENTS}

I wish to thank Doctors Richard D. Tocher and Robert 0 . Tinnin for their guidance and advice during the course of this research.

I also wish to thank Dr. Donald M. Knutson of the U.S. Forest Service for his interest and assistance, and Mr. Richard Doty and Patrick Green for their technological assistance.

Special thanks go to my wife Caroline for her encouragement and support.

I gratefully acknowledge the support of the Collins Foundation for their financial assistance which made this research possible. 
TABLE OF CONTENTS

PAGE

ACKNOWLEDGMENTS $\ldots \ldots \ldots \ldots \ldots \ldots \ldots \ldots \ldots \ldots \ldots \ldots \ldots \ldots \ldots \ldots \ldots$

LIST OF TABLES $\ldots \ldots \ldots \ldots \ldots \ldots \ldots \ldots \ldots \ldots \ldots \ldots \ldots \ldots \ldots$ vi

LIST OF FIGURES $\ldots \ldots \ldots \ldots \ldots \ldots \ldots \ldots \ldots \ldots \ldots \ldots \ldots \ldots \ldots$ vii

INTRODUCTION $\ldots \ldots \ldots \ldots \ldots \ldots \ldots \ldots \ldots \ldots \ldots \ldots \ldots \ldots \ldots \ldots \ldots \ldots \ldots$

Environmental and Resource Implications ......... 10

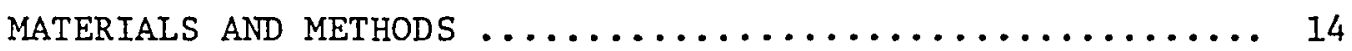

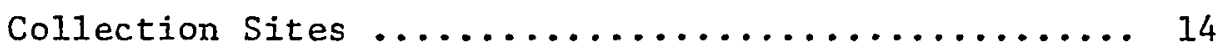

Extraction Procedures ..................... 17

Extraction Procedure I ............... 17

Extraction Procedure II ............... 18

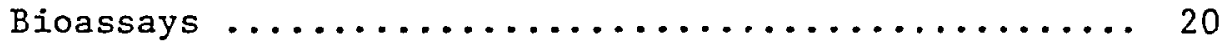

Pumpkin Seed Cotyledon Bioassay ........... 20

Amaranthus Bioassay $\ldots \ldots \ldots \ldots \ldots \ldots \ldots \ldots \ldots . \ldots \ldots$

Chromatographic Procedures ................. 23

Paper Chromatography ................. 23

Preparative Thin Layer Chromatography ....... 23

High Performance Thin Layer Chromatography ..... 24

Gas Liquid Chromatography $\ldots \ldots \ldots \ldots \ldots \ldots \ldots . \ldots 25$

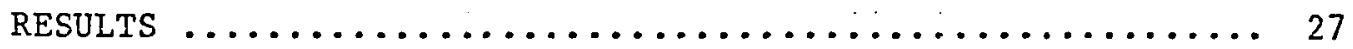

Extraction Procedure I .................... 27

Pumpkin Seed Cotyledon Bioassay ........... 27 
PAGE

Extraction Procedure II $\ldots \ldots \ldots \ldots \ldots \ldots \ldots \ldots \ldots . . \ldots$

Amaranthus Bioassay $\ldots \ldots \ldots \ldots \ldots \ldots \ldots \ldots . . \ldots$

Preparative Thin Layer Chromatography ....... 41

High Performance Thin Layer Chromatography .... 41

Gas Liquid Chromatography ............. 49

DISCUSSION AND CONCLUSIONS $\ldots \ldots \ldots \ldots \ldots \ldots \ldots \ldots \ldots \ldots \ldots$

Seasonal Fluctuations $\ldots \ldots \ldots \ldots \ldots \ldots \ldots \ldots \ldots \ldots \ldots$

Infected vs. Uninfected Material ............ 57

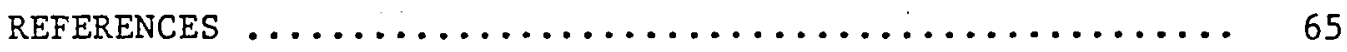

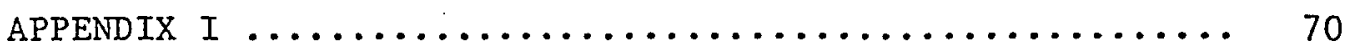




\section{LIST OF TABLES}

TABLE

PAGE

I. Total Losses from Disease by. Disease Group ....... 11

II. Annual Losses to Dwarf Mistletoe by Form of Loss .... 12

III. Annual Loss to Dwarf Mistletoe by Tree Species ...... 12

IV. Cytokinin Concentration from Amaranthus Bioassay .... 40

V. Rf Values for Samples Run in Solvent System I ..... 43

VI. Rf Values for Samples Run in Solvent System II ..... 46

VII. Rf Values for Samples Run in Solvent System III .... 48

VIII. Rf Values for Samples Run in Solvent System IV ..... 51

IX. Relative Retention Times for Cytokinin Standards .... 52

X. GLC Analysis of Samples from Extraction Procedure I . 53

XI. Cytokinin Concentration of Spring Samples as

Determined by GLC $\ldots \ldots \ldots \ldots \ldots \ldots \ldots \ldots \ldots \ldots$ 


\section{LIST OF FIGURES}

FIGURE

PAGE

1. Douglas-fir tree infected with $\underline{A}$. douglasii and showing many "witches' brooms" resulting from this infection $\ldots \ldots \ldots \ldots \ldots \ldots \ldots$

2. Douglas-fir trees that have died as a result of dwarf mistletoe infection $\ldots \ldots \ldots \ldots \ldots \ldots \ldots 4$

3. Some free bases of natural and synthetic cytokinins $\ldots \ldots \ldots \ldots \ldots \ldots \ldots \ldots \ldots \ldots \ldots \ldots \ldots$

4. Fifth growth segment of a branch from Douglasfir showing the aerial shoots of $\underline{A}$. douglasii with female fruits $\ldots \ldots \ldots \ldots \ldots \ldots \ldots \ldots \ldots$

5. Flow chart for Extraction Procedure I ........... 19

6. Flow chart for Fxtraction Procedure II ......... 21

7. Pumpkin seed cotyledon bioassays for cytokinins from $10 \mathrm{~g}$ fresh Douglas-fir tissue or the dwarf mistletoe A. douglasii $\ldots \ldots \ldots 28$

8. Pumpkin seed cotyledion bioassays for cytokinins extracted from $10 \mathrm{~g}$ fresh western hemlock tissue or the dwarf mistletoe

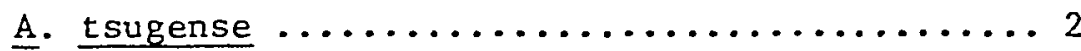

9. Cytokinin activity in extracts of healthy (I) and infected (II) Douglas-fix first year

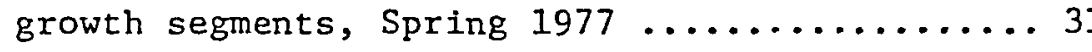


10. Cytokinin activity in extracts of healthy (I) and infected (II) Douglas-fir first year growth segments, Spring $1978 \ldots \ldots \ldots \ldots \ldots \ldots \ldots 32$

11. Cytokinin activity in extracts of healthy (I) and infected (II) Douglas-fir fifth year gorwth segments, spring 1977 ............ 33

12. Cytokinin activity in extracts of healthy (I) and infected (II) Douglas-fir fifth year growth segments, Spring $1978 \ldots \ldots \ldots \ldots \ldots \ldots \ldots . \ldots 34$

13. Cytokinin activity in extracts of $\underline{A}$. douglasii aerial shoots $\ldots \ldots \ldots \ldots \ldots \ldots \ldots \ldots \ldots \ldots \ldots \ldots$

14. Cytokinin activity in extracts of healthy (I) and infected (II) western hemlock tissue, Spring $1977 \ldots \ldots \ldots \ldots \ldots \ldots \ldots \ldots \ldots \ldots \ldots \ldots \ldots$

15. Cytokinin activity in extracts of healthy (I) and infected (II) western hemlock tissue, Spring $1978 \ldots \ldots \ldots \ldots \ldots \ldots \ldots \ldots \ldots \ldots \ldots \ldots \ldots \ldots \ldots$

16. Cytokinin activity in extracts of $\underline{A}$. tsugense aerial shoots $\ldots \ldots \ldots \ldots \ldots \ldots \ldots \ldots \ldots \ldots \ldots \ldots$

17. Cytokinin activity of typical winter samples of Douglas-fir (I) and western hemlock (II) .... 39

18. Rf zones for cytokinin standards and tissue extracts run in solvent system I on HP-TLC

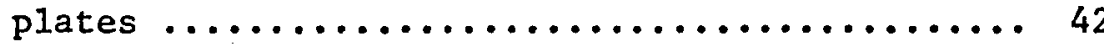


19. Rf zones for cytokinin standards and tissue extracts run in solvent system II on HP-TLC plates ..................... 45

20. Rf zones for cytokinin standards and tissue extracts run in solvent system III on HP-TLC plates $\ldots \ldots \ldots \ldots \ldots \ldots \ldots \ldots \ldots \ldots$

21. Rf zones for cytokinin standards and tissue extracts run in solvent system IV on HP-TLC plates ..................... 50 


\section{INTRODUCTION}

Dwarf mistletoes (Arceuthobium spp., family Viscaceae) are seed bearing flowering plants which are parasitic on conifers of the Pinaceae in the O1d and New Worlds and of the Cupressaceae in the Old World (Hawksworth and Wiens 1972). Parasitism in dwarf mistletoes is of a strictly obligate nature with the parasite being dependant upon the host for all of its water and mineral requirements and for most of its carbohydrates (dwarf mistletoes do contain chlorophyll and are capable of photosynthesizing to a limited degree) (Hull and Leonard 1964b; Miller and Tocher 1975).

Physiological contact with the host is maintained via the endophytic system whereby, haustoria invade the host branches and maintain close contact with the host tissue.

The initial symptom of a dwarf mistletoe infection may be the development of a small spindle-shaped swelling at the site of infection one or more years after initial penetration (Sharpf and Hawksworth 1968; Shea and Stewart 1972; Lightle and Weiss 1974). Swelling may be pronounced or inconspicuous. Aerial shoots of the parasite usually arise from the swelling after another one to two years. However, severe infection may occur without the shoots arising. As the endophytic system of the parasite becomes more extensive, the development of "witches brooms", the proliferation of many close weak branches on the host resulting from disruption of normal spical dominance, may occur, (figures 
1 and 2).

Witches brooms may be classified into two basic types (Hawksworth and Wiens 1972; Kuijt 1960):

1) Systemic types, in which the endophytic system grows along with the branch, with aerial shoots of the parasite scattered along the host branch, often concentrated in the fourth through sixth year growth segments; and

2) Nonsystemic or localized types in which the shoots remain concentrated near the original site of infection. The type of broom formation is relatively species constant, with the nonsystemic type being the more common.

A serious infection in a tree may exist without the development of a broom, but this is usually characterized by abundant shoots along the branches of the crown (Lightle and Weiss 1974).

The size of witches' brooms may vary considerably from those in young infections having only a few small branchlets to those with large masses of branches weighing several hundred pounds (Shea 1966). These may become large enough, as in Douglas-fir, to include the entire crown of the tree and may develop long drooping or trailing branches on their lower portions (Graham 1961). However, in older infections the upper part of the crown is usually dead or dying and nearly all the foilage is contained in the broomed branches (Scharpf and Hawksworth 1968; Graham, 1961).

This results in the typical spike tops (dead tops) seen in heavily infected Douglas-fir stands. The infected branches may have a greatly increased growth in diameter. It has been suggested that the broomed 


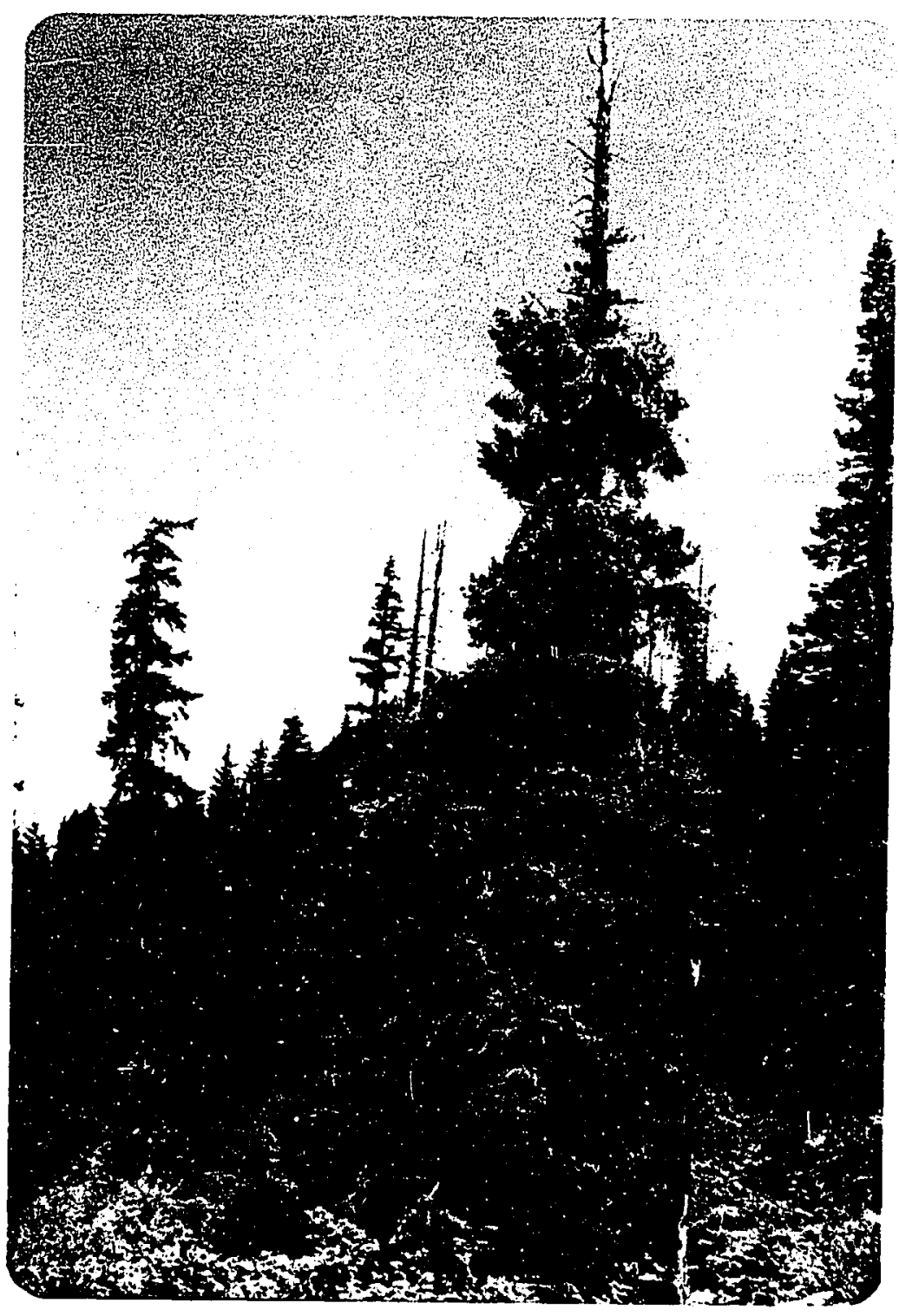

Figure 1. Douglas-fir tree infected with A. douglasii and showing many "witches' brooms" resulting from this infection. Note healthy trees in background. 


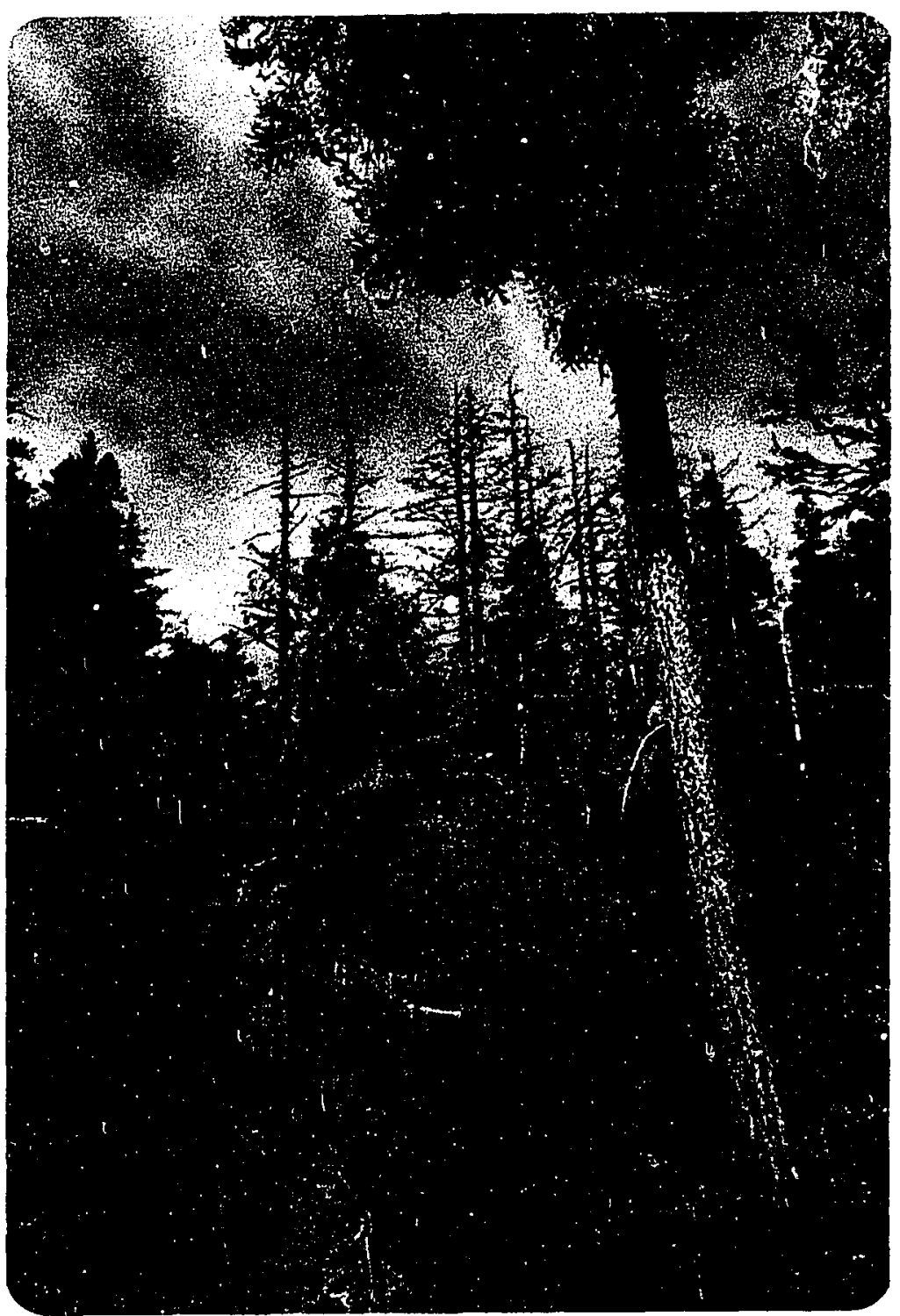

Figure 2. Douglas-fir trees that have died as a result of dwarf mistletoe infection. The abnormal branching pattern in the dead "witches' brooms" may be seen clearly. 
branches serve as a nutrient sink, diverting nutrients from the uninfected parts of the tree. The growing tops of the trees do not get needed nutrients, resulting in a loss of vigor and usually death of the upper part of the crown. Accordingly, broomed branches usually outlive their infected neighbors by many years (Hawksworth and Wiens 1972).

When the trunk of the tree is invaded by the endophytic system, other symptoms may occur. Old trunk infections may be characterized by large trunk cankers or by spindle shaped swellings of the trunk (Graham 1961; Shea and Stewart 1972). Seams in the trunk may appear associated with broomed branches (Shea 1966). Due to their large size, broomed branches often break off. The cankers and stubs of broomed branches can serve as entry points for decay-causing fungi and insects (Shea 1966; Kuijt 1955; Shea and Stewart 1972).

In 1966 Thimann and Sachs, in their pioneering work on the role of cytokinins in fasciation disease in peas, suggested the possibility that cytokinin might play a role in mistletoe infections. Other authors (Bidwell 1974; Hill 1973) have also made similar statements but to my knowledge this hypothesis has never been tested.

Cytokinins are a group of plant growth regulators which are potent inducers of nutrient mobilization, cell division, inhibition of senescence and, as antagonists of auxins, inhibitors of spical control. Because of these properties cytokinins have often been implicated in plant diseases since many diseases show symptoms that can be mimicked by cytokinins (see reviews by Daly and Knoche 1976; Sequeira 1973). 
Naturally occurring cytokinins are usually $N^{6}$-substituted adenine derivatives (Fig. 3), although such substances as diphenyl urea, isolated from coconut milk, also act physiologically in the same manner.

The generic name cytokinin is given to chemical substances which can stimulate cell division or cytokineses, in the manner of kinetin (Fig. 3), the first chemically defined cytokinin (Skoog and Armstrong 1970; Varner and Ho 1977). Kinetin is not a naturally occurring cytokinin but is derived from herring sperm DNA and has been identified as 6-furfury1aminopurine (Miller et.al. 1955). The first naturally occurring cytokinin to be isolated and identified was Zeatin (6-(4-hydroxy-3-methyltrans-2-butenylamino) purine) (Fig. 3) which was isolated from immature corn kernels (Letham et.al. 1964). Subsequent to this discovery a number of other naturally occurring cytokinins have been isolated from a variety of species (Fig. 3).

While cytokinins are considered to be hormones which regulate cell-division activities, their role in plants has gradually been recognized as being so widespread that it includes some aspects of every part of growth and development. There is also evidence that cytokinins play important roles in certain diseases. For example, "fasciation disease", caused by the bacterium Corynybacterium fascians, produces an abnormal flattening of host branches and an increase in the number of active lateral buds. The above responses have tentatively been shown to be the result of the production of cytokinins by the pathogen (Thimann and Sachs 1966). The fungus, Taphrina cerasi, which causes "witches' brooms" in a number of hosts has also been shown to produce the cytokinin zeatin when cultured in artifictal media (Barthe and Bulard 1974). 
A number of other brooming responses have also been attributed to the action of cytokinins (Skoog and Armstrong 1970; Hill 1973).

This study was designed to investigate the role of cytokinins in two species-of dwarf mistletoe and their respective infected and healthy hosts. Of the two species chosen, $\underline{A}$. douglasii which infects Douglas-fir, produces asystemic infection and $A$. tsugense, which infects western hemlock, a non-systemic infection. The main objectives were to determine: 1) the levels of cytokinins (both activity and concentration); 2) seasonal variation cytokinin levels; and 3) the individual cytokinins present in the various tissues samples. This was accomplished using various extraction procedures, bioassays and chromatographic techniques. I felt that cytokinins and possibly other growth regulators played an importart role in the dwarf mistletow infection.

A number of the host responses to dwarf mistlecoe infection are quite similar to the known effects of cytokinins acting alone or in combination with other hormones. The most obvious is the loss of apical control in those hosts having a systemic type of infection. This type of infection is common in Douglas-fir (Pseudotsuga menziesii) and 1odgepole pine (Pinus contorta) (Kuijt 1960). The infected host buds also, tend to break dormancy earlier in the year and tend to remain active for a longer period of time than is the case for the uninfected hosts (Kuift 1960). Both of these actions have been simulated in other plant material by the application of cytokinins alone, or in conjunction with other hormones (Steward and Krikorian 1971). As host trees begin to succumb to the infection, infected branches tend to live and stay green for a 
longer period of time than healthy branches (Kuijt 1960). This type of response may be looked upon as an example of the "green island" effect in which application of cytokinins can cause a delaying of senescence and the typical yellowing that follows (Steward and Krikorian 1971; Hill 1973). In those host species showing localized or nonsystemic types of infection such as western hemlock (Tsuga heterophyla) and ponderosa pine (Pinus ponderosa), the host does not show loss of spical dominance but does show a large area of swelling in the region of infection (Kuijt 1960). This swelling is due in part to increased cell division and is the type of response that could be expected from increased cytokinins (Sequeira 1973).

Another aspect that I believe fiould be emphasized is the ability of cytokinins to cause mobilization of nutrients. With at least two fungal diseases it has been shown that there is a mobilization of nutrients from the healthy tissue to the areas of infection (Sequeira 1973; Daly and Knoche 1976). This could be a highly important function in the dwarf mistletoe host-parasite relationship since it appears that dwarf mistletoes are almost entirely dependant on their hosts for their nutritional needs (Miller and Tocher 1975; Hull and Leonard 1964a and 1964b). Indeed, both Hull and Leonard (1964a) and Greenham and Leonard (1965) have shown that substantial amounts of both carbohydrates and amino acids are shunted from the host to the parasite.

It should also be emphasized that it is difficult to attribute any one response to a single hormone. Often these plant growth substances act synergistically or antagonistically and in some cases there may be 
as many as four substances involved in a single reaction (Hill 1973). Often growth substances will vary with the seasons. One substance will be synthesized rapidly with consequent reduction in another.

ENVIRONMENTAL AND RESOURCE IMPLICATIONS OF THIS STUDY

Although dwarf mistletoe can be seen to have an adverse effect on lumber quality, by far the most serious effect of the parasite is in the unrealized timber production caused by its presence. Dwarf mistletoe is known to reduce both height and diameter growth and thus reduce the yield of an infected stand. Haglund and Dooling (1972) found in a comparison of an infected stand of Douglas-fir with a similar uninfected stand that the uninfected stand produced 1.5 times the board foot volume in one half the time. In a stem analysis of 30 western hemlock trees, averaging 110 years old, Smith (1969) found that lightly infected trees had $41 \%$ greater volume growth and $84 \%$ greater height growth in a seven year period than severely infected trees. The timber loss due to dwarf mistltoes in the western United States is estimated to total 3.2 billion board feet annually (Shea and Howard 1969). At 1970 prices this would total approximately $\$ 75$ million.

Forest diseases in Oregon and Washington cause an estimated loss of 403 million cubic feet in annual forest productivity. Dwarf mistletoes are the largest single category, accounting for an annual average loss of 148 million cubic feet, or $37 \%$ of the total loss to disease (Childs and Shea 1967). This is equivalent to the amount of lumber used to build 82,000 average homes (Stewart and Shea 1971). Other diseases 
causing timber loss are root rots and other diseases, including foilage diseases, stem rusts, etc. (Table I).

TABLE I

Total Losses from Disease by Disease Group.

\begin{tabular}{lcc}
\hline & Million cubic feet & Thousand average homes* \\
Dwarf Mistletoes & 148 & 82 \\
Root Rots & 115 & 64 \\
Heart Rots & 110 & 61 \\
Other & 30 & 17 \\
Total & 403 & 224 \\
\hline
\end{tabular}

*0ne average home $=11,000$ board feet or 1800 cubic feet.

(Table compiled from Childs and Shea, 1967)

Loss from tree diseases can be classified as: 1) growth loss growth that would have occurred if a disease was not present; 2) mortality - trees that die because of disease; and 3) cull - wood made unusable by disease (Stewart and Shea 1971). Loss from dwarf mistletoe in Oregon and Washington is almost entirely due to growth and mortality, with cull loss being negligible (Childs and Shea 1967) (Table II).

By tree species, Douglas-fir has the greatest annual losses to dwarf mistletoe, followed by western hemlock and ponderosa pine (Table III) . 
TABLE II*

Annual Losses to Dwarf Mistletoe by Form of Loss

\begin{tabular}{lc} 
& Million Cubic Feet \\
Growth Loss & 75 \\
Mortality & 72 \\
Cull & Negligible \\
Total & 148 \\
\hline
\end{tabular}

*Compiled from Childs and Shea 1967.

TABLE III*

Annual Losses to Dwarf Mistltoe by Tree Species

\begin{tabular}{lc} 
& Million Cubic Feet \\
Douglas-fir & 46 \\
Western Hemlock & 42 \\
Ponderosa Pine & 29 \\
True Firs & 11 \\
Miscellaneous & 20 \\
Total & 148 \\
\hline
\end{tabular}

*Compiled from Childs and Shea 1967. 
Control of dwarf mistletoe can be seen as a means of increasing timber yields in order to offset increasing demands for forest products. Control methods can be placed into three categories: 1) Silvicultural, or harvesting and replanting methods; 2) Biological methods, involving the use of organisms which attack, feed on, or some other way affect the growth and spread of dwarf mistletoe; and 3) Chemical methods, involving the use of herbicides to selectively kill the parasite.

To date, the only method that works is the silvicultural. In order for the latter two methods to be successful more basic knowledge concerning the physiology of the host parasite relationship is required. It is one of the goals of this work to shed some light on what could be a simple and direct method for control of the dwarf mistletoe. 
MATERIALS AND METHODS

\section{Collection Sites}

Locations for obtaining samples were established at two different sites in the Mt. Hood National Forest. Douglas-fir collection sites were in the area around the Bear Springs ranger district. This area contains numerous Douglas-fir dwarf mistletoe infected and healthy trees which were deemed suitable for sampling. Western hemlock was collected from the Goat Mountain area, a location with numerous infected and uninfected specimens.

At each site, fourteen infected trees were chosen and tagged for future reference. Each of these trees was of approximately the same age, as determined by height estimates and the diameter at breast height. The above number of trees was needed in order to collect enough material from the aerial shoots of the dwarf mistletoe for the extraction procedures. At the same site, ten uninfected trees were chosen to serve as controls. These resembled the infected trees as closely as possible.

Tissue samples from the above were collected by removing the portion of the branch to be investigated with pruning shears or a hand saw. The needles were removed by hand and the appropriate samples were cut and weighed to the nearest gram and placed in vacuum bottles containing ice $\operatorname{cold}\left(-10^{\circ} \mathrm{C}\right) 80 \%$ ethanol (see section on extraction procedures). Aerial shoots of the dwarf mistletoe were hand picked and treated in the same manner as other tissue. 
These collections were made on a seasonal basis, i.e., Fall, Winter, Spring and Summer. Fall samples were collected after the first frosts of the year which, at this altitude, occurred in late September. Winter samples were collected in mid-February. The time of collection for Spring samples was based on the condition of the buds. The buds were monitored weekly during April, May and June to determine when swelling was taking place and collections were made just prior to bud break. This occurred in late May in infected Douglas-fir and in mid-June for the uninfected Douglas-fir. Bud break in infected western hemlock took place in early May and occurred in the first week of June in the uninfected trees. Spring and Winter samples were collected over two growing seasons.

In the case of $\underline{P}$. menziesii (a systemic type of infection occurs on this host) male and female aerial shoots of $\underline{A}$. douglasil and the first and fifth yearly segments were collected. (A segment refers to a single years growth length of a conifer branch or stem and is sometimes incorrectly called an internode (Fig. 4).) The first segment sample contained the dormant bud in the Winter, Summer and Fall collections. In Spring collections the bud is no longer dormant but is undergoing active growth.

In the case of western hemlock, a species which has a non-systemic type of infection, only aerial shoots of the mistletoe and the localized area of infected tissue were collected from the infected trees. In uninfected western hemlock a segment of the branch was collected that was of the same size as that from the infected branch and the same distance from the main trunk. 


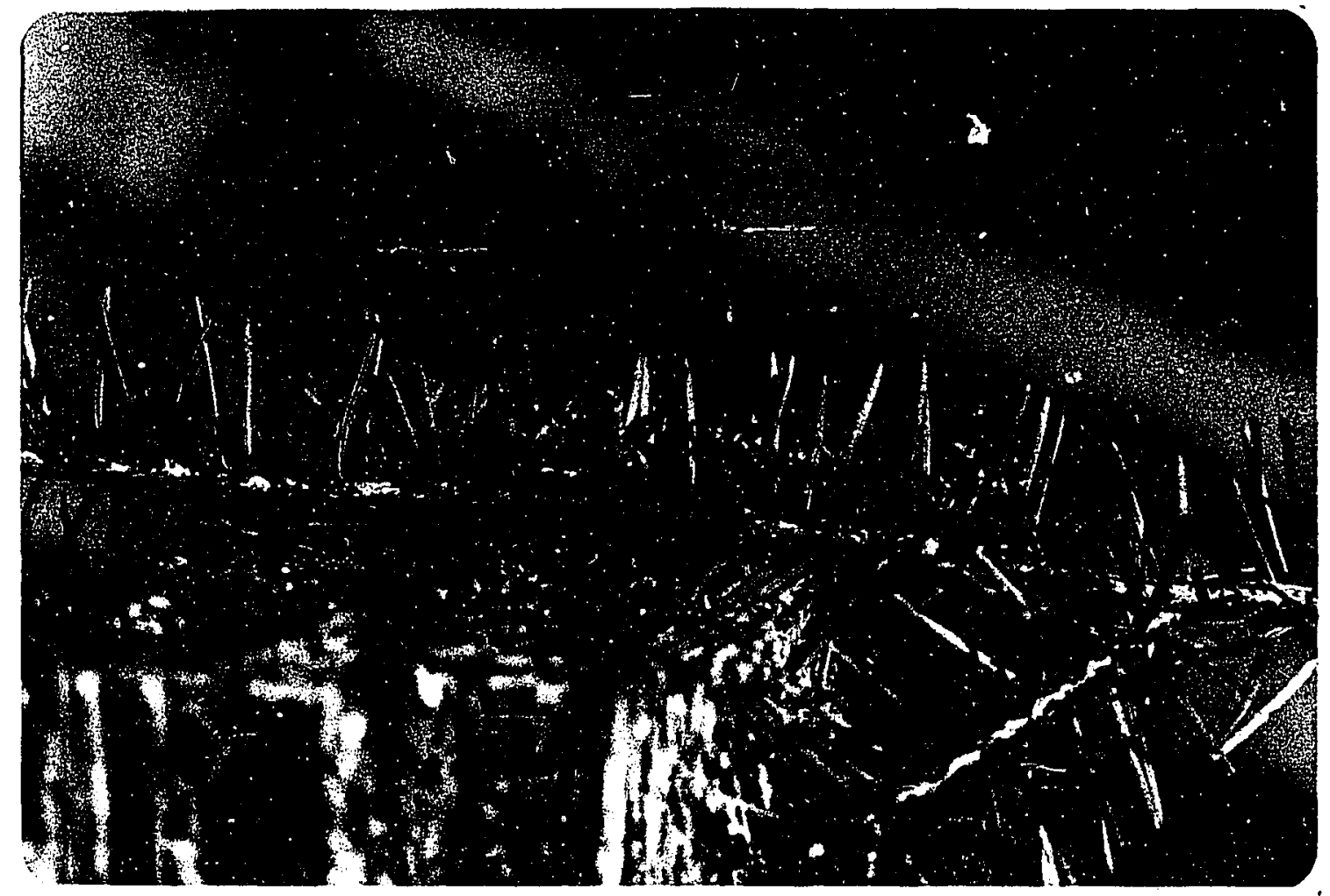

Figure 4. Fifth growth segment of a branch from Douglas-fir showing the aerial shoots of $A$. douglasii with female fruits. Portions of the third and sixth growth segments may be seen on the left and right respectively. 
Extraction Procedures

Initial extraction was begun in the field by placing the weighed samples in $100 \mathrm{ml}$ of ice cold $80 \%$ ethanol in individual vacuum bottles. This procedure was used as the starting point in both of the following methods.

\section{Extraction Procedure I}

Fifty to 100 samples from the vacuum bottles were ground in $80 \%$ ice cold ethanol $(20 \mathrm{ml} / \mathrm{g}$ of tissue including the ethanol from the vacuum bottles) in a Waring blender for 10 minutes. The samples were then extracted $80 \%$ ethanol for 24 hours at $-20^{\circ} \mathrm{C}$. At the end of this period the samples were vacuum filtered on Whatman's number 42 filter paper and the filtrate was stored in the freezer $\left(-20^{\circ} \mathrm{C}\right)$ for further extraction. The extraction procedure was carried out two more times and all of the filtrates were combined.

The ethanol extract was evaporated to the $\mathrm{H}_{2} \mathrm{O}$ phase under vacuum at $37^{\circ} \mathrm{C}$ in a rotary flash evaporator. The $\mathrm{H}_{2} \mathrm{O}$ phase was then adjusted to $\mathrm{pH} 8.6$ with $1 \mathrm{~N} \mathrm{NaOH}$ and extracted with ethyl acetate (2 volumes) three times. The remaining $\mathrm{H}_{2} \mathrm{O}$ phase was discarded and the ethyl acetate phase was evaporated to dryness under vacuum at $37^{\circ} \mathrm{C}$ and the remaining residue was dissolved in $80 \%$ ethanol. The ethanol fraction was reduced to the $\mathrm{H}_{2} \mathrm{O}$ phase under vacuum at $37^{\circ} \mathrm{C}$ and this phase was then extracted three times with ethyl acetate (2 volumes).

The ethyl acetate phase was discarded and the water phase was adjusted to $\mathrm{pH} 5.5$ with $1 \mathrm{~N} \mathrm{HCl}$ and extracted three times with water saturated $\underline{n}$-butanol ( 3 volumes). The Water fraction was discarded and 
the $\mathrm{n}$-butanol fractions were combined and concentrated to $5 \mathrm{ml}$ under vacuum at $37^{\circ} \mathrm{C}$. The samples were then stored at $-20^{\circ} \mathrm{C}$ for further analysis. This procedure purportedly removes the other major plant growth substances, such as auxins, gibberellines and abscisic acid, that might interfere with bioassays (Shindy and Smith 1975). A flow chart is presented in Figure 5.

\section{Extraction Procedure II}

Fifty to $100 \mathrm{~g}$ samples of tissue from vacuum bottles were ground in ice cold $80 \%$ ethanol $(20 \mathrm{ml} / \mathrm{g}$ of tissue including the ethanol from the vacuum bottle) for 24 hours at $-20^{\circ} \mathrm{C}$. The extract was filtered on Whatman's number 42 filter paper and the supernatant solution was returned to the freezer. The filter paper and the residue were stirred for one hour with a fresh volume of $80 \%$ ethanol. This mixture was then filtered and the procedure was again repeated. All of the supernatant solutions were combined and reduced to $5 \mathrm{mI}$ in vacuo at $45^{\circ} \mathrm{C}$ and then centrifuged for 15 minutes at $2000 \times \mathrm{g}$. The supernatant solution was removed and the pellet was washed with $5 \mathrm{ml}$ of distilled $\mathrm{H}_{2} \mathrm{O}$. The supernatant and the washings were combined and loaded on a polyvinylpyrrolodone (PVP) (Polyclar AT, GAF Corp.) column (15 x $2.5 \mathrm{~cm}$.) which had been prewashed with $\mathrm{pH} 5.0$ citrate buffer, $0.1 \mathrm{M}$. The column was then eluted with $215 \mathrm{ml}$ of the same buffer of which the final $125 \mathrm{ml}$ volume was retained as sample (Carlson and Larson 1977).

The above sample volume was dried in vacuo at $50^{\circ} \mathrm{C}$ and the residue was taken up in $5 \mathrm{ml}$ of $\mathrm{H}_{2} \mathrm{O}$. The $\mathrm{pH}$ was adjusted to 2.5 with $1.0 \mathrm{~N}$ HCl and loaded on a cation exchange resin column, $30 \mathrm{ml}$ bed volume; 
FROZEN TISSUE

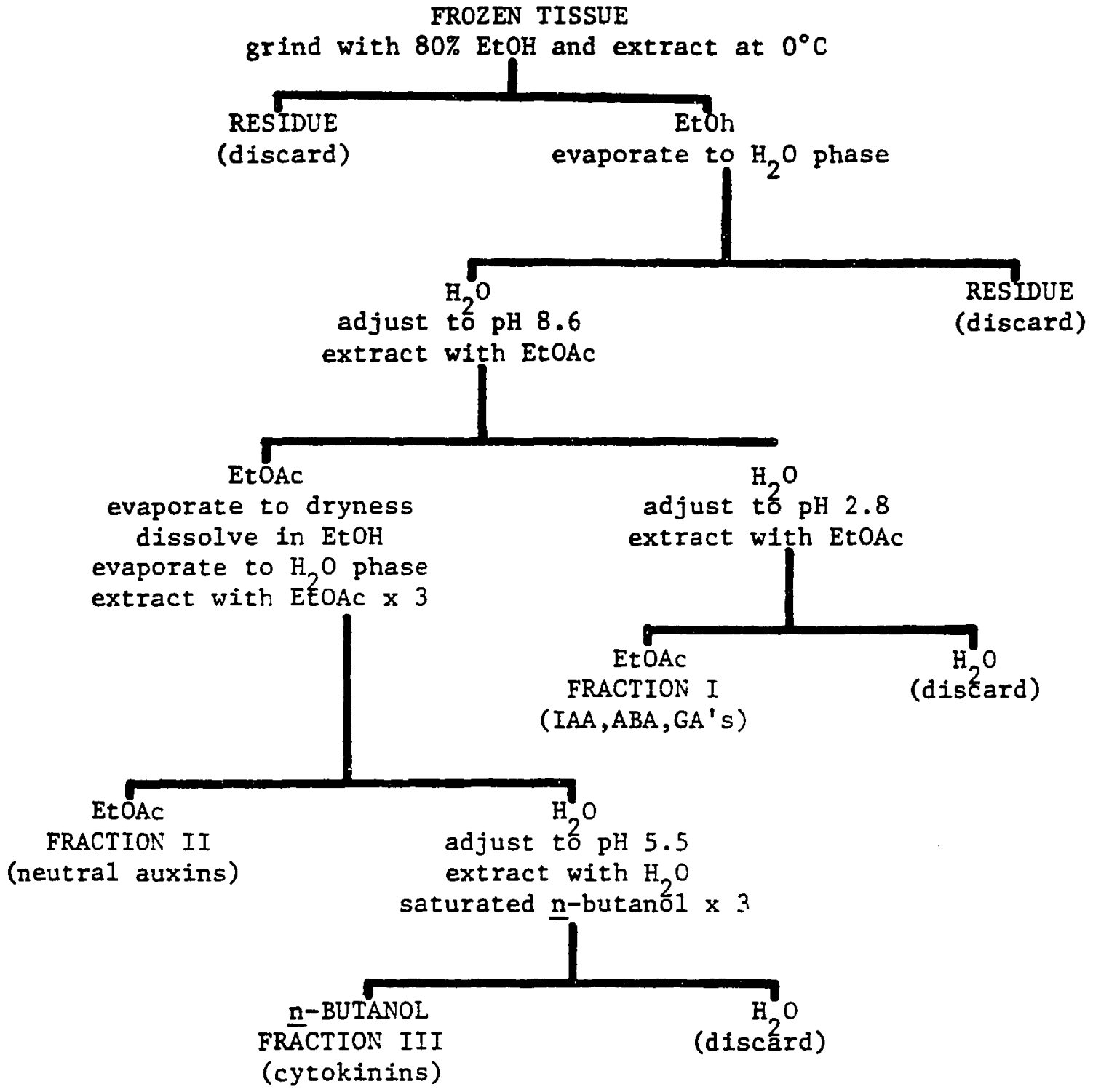

Figure 5. Flow chart for solvent extraction procedure I. 
(Dowex 50W-X8 H${ }^{+}$form, 200-400 mesh). The colum was washed with 150 $\mathrm{ml} 70 \%$ ethanol and then $150 \mathrm{ml}$ of distilled $\mathrm{H}_{2} \mathrm{O}$. Compounds responsible for cell division activity were eluted from the column with $250 \mathrm{ml}$ of $5 \mathrm{~N} \mathrm{NH} 4 \mathrm{OH}$. The ammonia was removed by evaporation in vacuo at $50^{\circ} \mathrm{C}$. The residue was taken up in $3 \mathrm{ml}$ of $35 \%$ ethanol and stored in the freezer for use in chromatography and in bioassays (Hewett and Wareing 1973). This method of extraction has an advantage over the first in that it employs PVP which is a useful agent in removing phenolic compounds that could interfere with bioassay procedures. A flow chart is provided in Figure 6.

\section{Bioassays}

Pumpkin Seed Cotyledon Bioassay

This bioassay is essentially a modification of the Cucumber cotyledon assay of Fletcher and McCullagh (1971) and is based on the cytokinin induced formation of chlorophyl1 in etiolated cotyledons. Pumpkin seeds are used because of their larger size and ease in handling (Fox, personal communication).

Pumpkin seeds were sown in vermiculite that was in plastic greenhouse trays. The vermiculite was watered with distilled water until saturated and the trays were sealed in opaque plastic bags and placed in an unlighted growth chamber at $25^{\circ} \mathrm{C}$. The seeds were allowed to germinate for six days. At the end of this period the trays were removed from the plastic bags and placed under a dim green light for the removal of the cotyledons. Only cotyledon palrs with a maximum degree of hook angle were chosen for bioassays. 
TISSUE SAMPLES

grind and extract 3 times in $80 \% \mathrm{EtOH}$ C $0^{\circ} \mathrm{C}$.
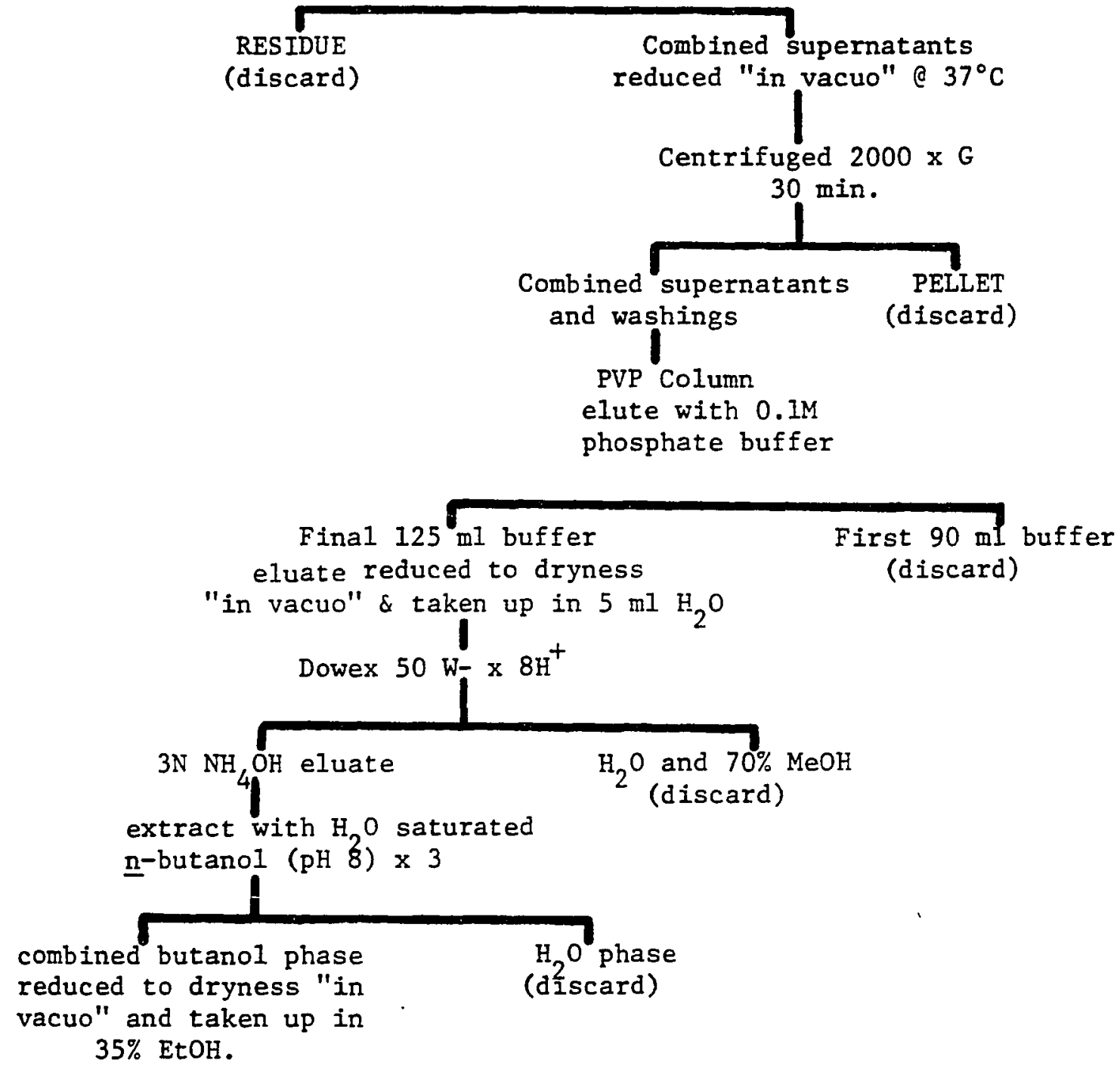

Figure 6. Flow Chart for Extraction Procedure II. 
Five cotyledon pairs were placed in $5 \mathrm{~cm}$. glass petri dishes which were lined with a double thickness of Whatman 3M filter paper. Two mI of $\mathrm{M} / 75$ phosphate buffer, $\mathrm{pH} 6.3$, and containing the appropriate cytokinin standards was added to the petri dishes and these were returned to the dark for 14 hours at $38^{\circ} \mathrm{C}$. At the end of this time period the cotyledons were illuminated with fluorescent light at an intensity of $220 \mathrm{ft}-\mathrm{c}$. After 3 hours the chlorophyll was extracted with $90 \%$ acetone with $2.0 \mathrm{ml}$ of $\mathrm{NH}_{4} \mathrm{OH}$ per liter, saturated with $\mathrm{MgCO}_{3}$. The volume was brought up to $10 \mathrm{ml}$ and the chlorophyll levels determined by measuring the absorbance at $665 \mathrm{~nm}$.

Extracts from extraction procedure I were tested in this system by adding $1.5 \mathrm{ml}$ of the appropriate sample to the filter paper discs and allowing them to air dry. The discs were then placed in the petri dishes with the cotyledons and $2.0 \mathrm{ml}$ of the buffer solution.

Amaranthus Bioassay

This bioassay is based on the formation of betacyanin in the cotyledons and terminal portion of the hypocotyl of Amaranthus caudatum (Biddington and Thomas 1973). This reaction is considered to be highly specific for cytokinins (Challice 1977).

Seeds were purchased from the Nichols Seed Co. of Albany Oregon. The seeds were sown in plastic boxes on two layers of Whatman 3MM filter paper moistened with distilled water, and germinated in a dark growth chamber at $25^{\circ} \mathrm{C}$ for 72 hours. The seed coats were removed and explants consisting of the upper portion of the hypocotyl plus the cotyledons were cut from the seedlings. These explants were used as the bioassay 
sections, sets of ten being transferred to transparent polystyrene bioassay boxes. Each box contained two layers of Whatman 3MM filter paper moistened with $2 \mathrm{ml}$ of $\mathrm{M} / 75$ phosphate buffer at $\mathrm{pH} 6.3$ and containing $1 \mathrm{mg} / \mathrm{ml}$ tyrosine and the cytokinin to be assayed. The boxes were incubated at $25^{\circ} \mathrm{C}$ for 18 hours in the dark, after which the explants were removed and placed in $2.0 \mathrm{ml}$ of distilled water. Betacyanin was extracted by means of two cycles of freezing and thawing and the quantity determined by calculating the difference between the optical densities at $542 \mathrm{~nm}$ and $620 \mathrm{~nm}$.

The plant extracts were tested by cutting paper chromatograms (see section on paper chromatography) into ten equal Rf segments and placing each segment in a bioassay box. The bioassay procedure already described was then followed with the omission of the cytokinins to the buffer solution.

Chromatographic Procedures

Paper Chromatography

Paper chromatography was performed on $20 \times 20 \mathrm{~cm}$. Whatman $3 M M$ chromatography paper. The solvent system was isopropanol: ammonia: water (10:1:1) (Van Staden 1976). One $\mathrm{ml}$. of extract was applied to the origin as a streak. After development, the chromatogram was thoroughly dried in a stream of air, divided into ten equal Rf strips and these were then assayed for cytokinin activity in the Amaranthus bioassay.

Preparative Thin Layer Chromatography

Preparative thin layer chromatography was carried out using $20 \mathrm{x}$ $20 \mathrm{~cm}$. glass plates pre-coated with a $1.0 \mathrm{~mm}$. layer of silica gel F-254 
(EM Laboratories, Inc., Elmsford, New York). Each extract $(1.0 \mathrm{~m} 1)$ was applied as a streak and separated with n-butanol: $1 \mathrm{~N} \mathrm{NH}_{4} \mathrm{OH}$ : Water (7: 1:2) (Carlson and Larson 1977). Four cytokinin standards were spotted at the right hand edge of the plate and run with the samples for reference. At the end of the run the plates were air dried and the spots corresponding to the cytokinin standards were located under U.V. light $(254 \mathrm{~nm})$. The area of the plate that corresponded to the Rf zones of the standards was scraped off and extracted in $80 \%$ ethanol. These extracts were used for high performance thin layer chromatography or converted to their trimethylsilyl derivatives for gas chromatography.

High Performance Thin Layer Chromatography (HP-TLC)

HP-TLC bears the same relationship to ordinary TLC as High Performance Liquid Chromatography to ordinary liquid chromatography. HPTLC plates are coated with a thinner layer of absorbent which has been optimized for separation of samples in the nanoliter range. Particle size distribution is extremely narrow, much narrower than that of standard pre-coated plates. The layer density of an HP-TLC plate is comparable to that of a well packed HPLC column. Samples can be separated after a migration distance of only 3-6 cm. More than five compounds per minute can be separated because of the higher resolution resulting from the very low theoretical plate heights.

HP-TLC was carried out using four different solvent systems. In all systems the plates used were $10 \times 10 \mathrm{~cm}$. glass plates pre-coated with a $0.2 \mathrm{~mm}$ layer of silica gel 60 F-254 (E.M. Laboratories, Inc., Elmsford, - New York). Solvent system I was $\underline{n}$-Butanol: acetic acid: water $(12: 3: 5)$. 
Solvent system II was Isopropanol: Ammonia: water (10:1:1). Solvent system III was water saturated n-butanol. Solvent system IV was chloroform: methanol $(9: 1)$. The HP-TLC plates were kept in a desicator and were activated at $100^{\circ} \mathrm{C}$ for 30 minutes just prior to use. The plates were spotted with a microliter syringe and run to a solvent height of 3-5 cm. After running the plates were air dried and spots were located under U.V. light $(254 \mathrm{~nm}$.$) .$

Gas Liquid Chromatography

Silylation: Aliquots $(0.5-1.0 \mathrm{~m} 1)$ from each of the fractions of extraction procedure $I$ or $1 \mathrm{mg}$ samples of authentic cytokinin standards were placed in $1 \mathrm{ml}$ reactivials, dried under a nitrogen stream and dissolved in $100 \mu 1$ of $\mathrm{N}$, 0-bis-(trimethylsilyl) acetamide (BSA) (Klebe, et.al., 1966). The vials were immediately capped and heated in an oven at $70^{\circ} \mathrm{C}$ for 30 minutes.

One to ten $\mu 1$ of each trimethylsilyl derivative was injected into a F\&M model 700 dual column gas chromatograph equipped with dual flame ionization detectors and a temperature programmer. The columns were matching stainless steel column ( $3 \mathrm{~mm} \times 150 \mathrm{~cm}$ ) packed with $3 \% \mathrm{QF}-1$ on 60/80 mesh Chrom Q (Analabs). The GLC was operated under the followIng conditions: Hydrogen flow $30 \mathrm{ml} / \mathrm{min}$. for the sample column and 28 $\mathrm{ml} / \mathrm{min}$. for the reference column; air flow, $200 \mathrm{ml} / \mathrm{min}$. for both columns; nitrogen carrier gas flow $30 \mathrm{ml} / \mathrm{min}$. in the sample column and $24 \mathrm{~m} 1 / \mathrm{min}$. in the reference column; injector temperature, $200^{\circ} \mathrm{C}$; and detector temperature $275^{\circ} \mathrm{C}$. Temperature programming started at $100^{\circ} \mathrm{C}$ and increased linearly to $250^{\circ} \mathrm{C}$ at the rate of $4^{\circ} \mathrm{C} / \mathrm{min}$. (Shindy and Smith 1975). 
Retention time was recorded for each peak and compared to those of TMS derivatives of authentic standards.

A second set of GLC runs was performed using the same standards as above but in this case both the standards and the samples were spiked with $0.1 \mu 1$ of chromatographic grade pyrene which had been silylated as described above (Most et.al., 1968). Relative retention times were determined from the chromatograms relative to the retention time of the TMS pyrene. 


\section{RESULTS}

\section{Extraction Procedure I}

Pumpkin Seed Cotyledon Bioassay

Extracts (extraction procedure I) from 32 tissue samples were screened for cytokinin activity by the pumpkin seed cotyledon bioassay. This bioassay is not as specific as others but is quite rapid and was therefore used as a preliminary test to indicate which samples would be analyzed in further detail. The results are presented in figures 5 and 6 . In all cases cytokinin activity, as indicated by increased chlorophyll content, was highest in the Spring collected samples and lowest in the Winter samples. The outstanding pattern seen was the large increase in cytokinin activity in the Spring collected aerial shoots, fifth growth segments and infected western hemlock tissue as compared with healthy tissue. Extracts of the Summer and Fall material showed only small amounts of activity compared with those from the Spring. GLC analysis of the above extracts indicated that compounds having the same retention times as cytokinin standards were present.

Based on the results of the foregoing observations, I decided to carry out more detailed studies on Spring and Winter samples since these represented the extremes of cytokinin activity. 


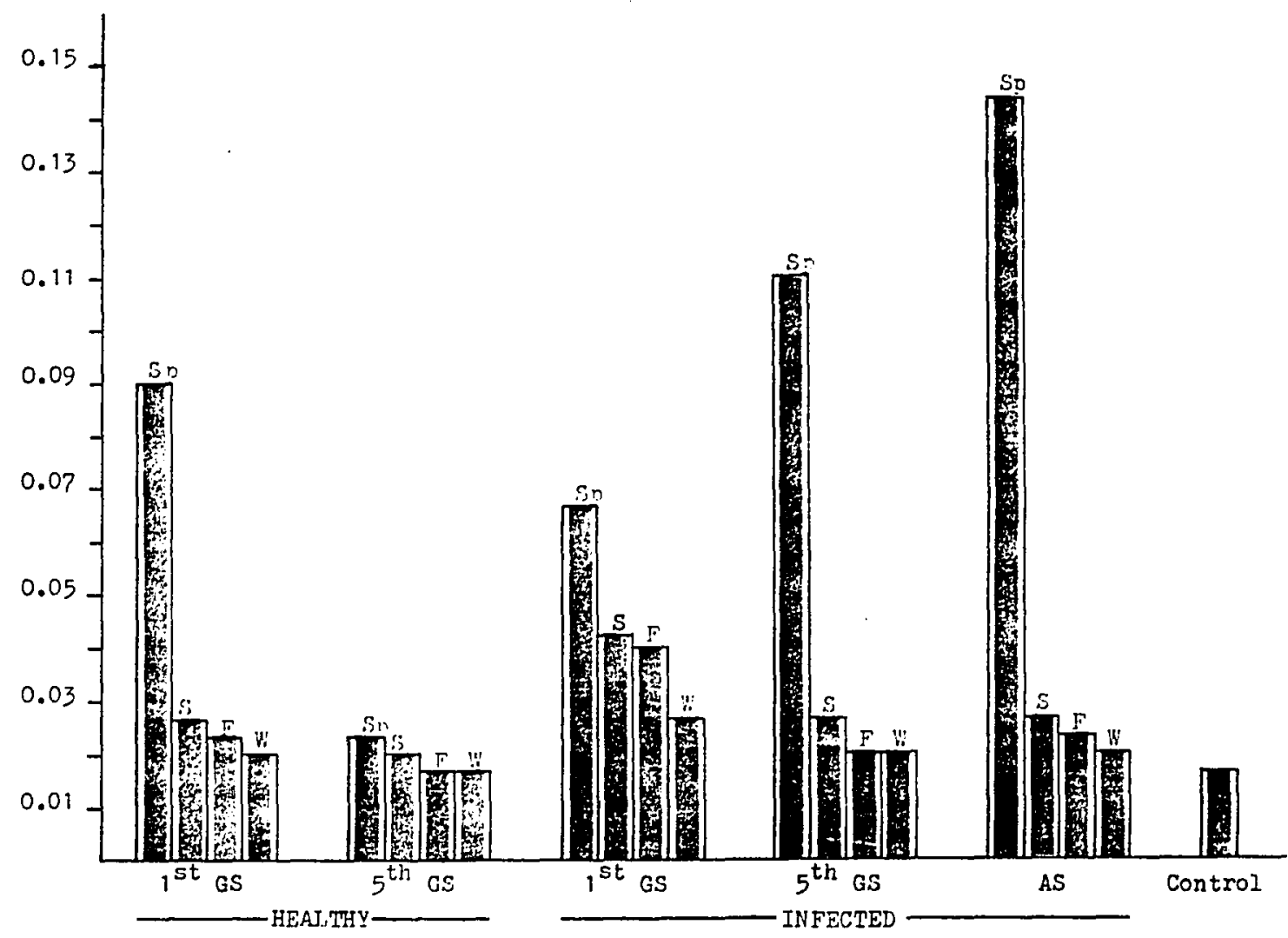

Figure 7. Pumpkin seed cotyledon bioassays for cytokinins extracted from $10 \mathrm{~g}$ fresh Douglas-fir tissue or the dwarf mistletoe A. douglasil. The results presented are averages from 5 replicates. AS = aerial shoots, GS = grwoth segment, $\mathrm{Sp}=$ Spring, $\mathrm{S}=$ Summer $, \mathrm{F}=\mathrm{Fall}, \mathrm{W}=$ Winter, Control $=$ untreated cotyledons. 


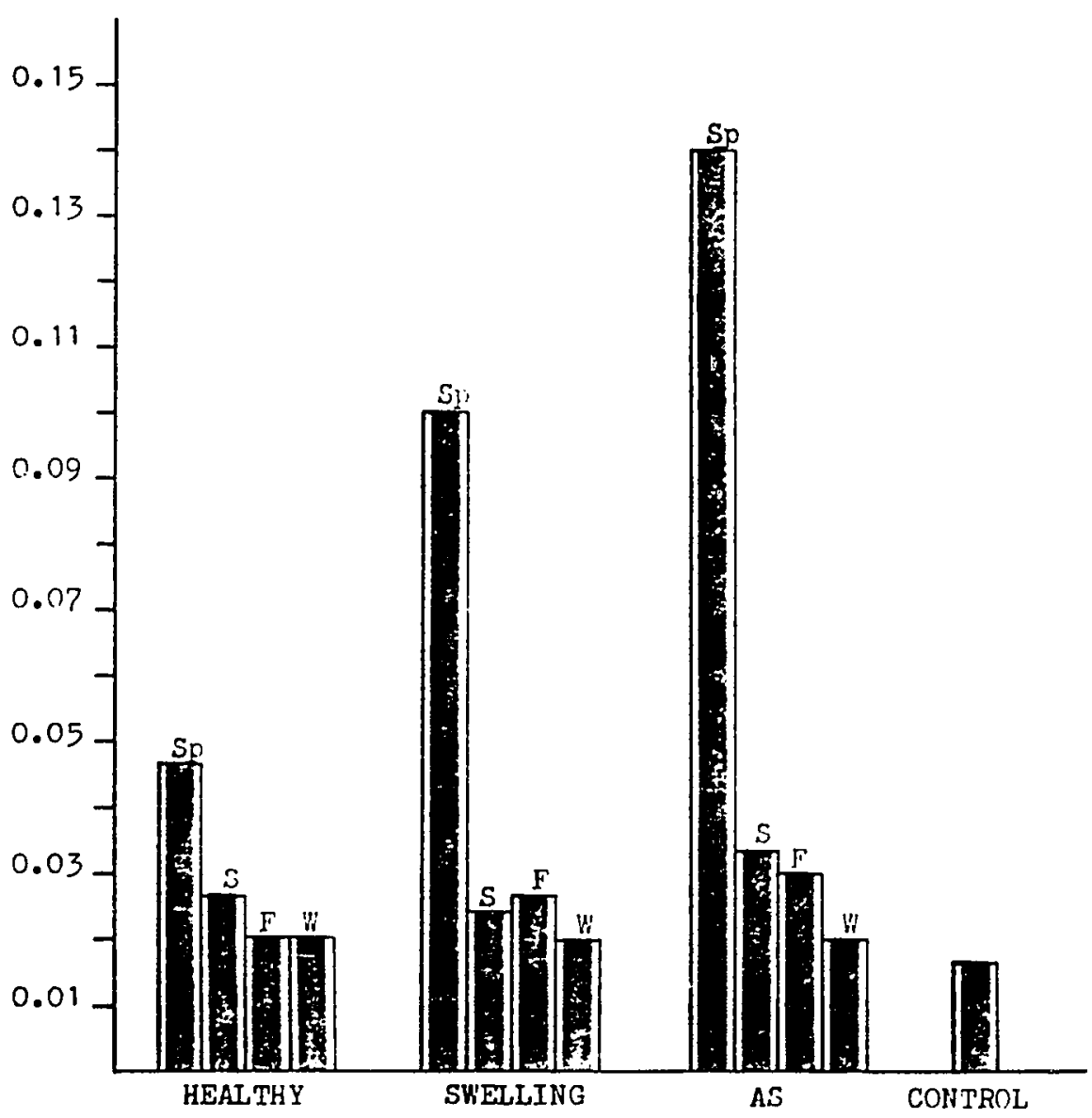

Figure 8. Pumpkin seed cotyledon bioassays for cytokinins extracted from $10 \mathrm{~g}$ fresh western hemlock tissue or the dwarf mistletoe A. tsugense. The resutls presented are averages from 5 replicates. AS $=$ aerial shoots, $G S=$ grwoth segment, $S p=$ Spring, $S=$ Summer $, F=F a l 1, W=$ Winter, Control = untreated cotyledon. 


\section{Extraction Procedure II}

Amaranthus Bioassay

Samples from Spring and Winter of two different seasons (19761977 and 1977-1978) were tested for cytokinin activity using the Amaranthus bioassay. The results are presented in Figures 9 through 17 . These graphs show average values from ten separate bioassays run for each sample. Statistical analysis (paired $t$ test) of the cytokinin activity indicated by betacyanin production showed a significant difference in cytokinin activity levels between healthy and infected Spring tissue (significant at the 0.05 level) in all cases except for the first growth segments. Since the cytokinin activity in the Winter samples appeared to be near zero, no statistical analysis was performed.

Total cytokinin concentration, expressed as $\mu \mathrm{g}$ BAP equivalents per gram, fresh weight was calculated for all Spring samples and is presented in Table IV. A second set of calculations for cytokinin concentration was made using only the 0.5 to $1.0 \mathrm{Rf}$ zones since these comprised the areas to which the cytokinin standards ran. These results are also presented in Table IV.

The outstanding feature seen in these data is the large difference in cytokinin activity and concentration between healthy and infected material, with the exception of the first year growth segments. These differences ranged from a high of about $2.0 \mathrm{\mu g}$ BAP equivalents per gram gresh weight in aerial shoots and infected fifth growth segments to a low of $0.15 \mu \mathrm{g}$ BAP equivalents per gram fresh weight in uninfected material from fifth year growth segments. In all cases where differences were 

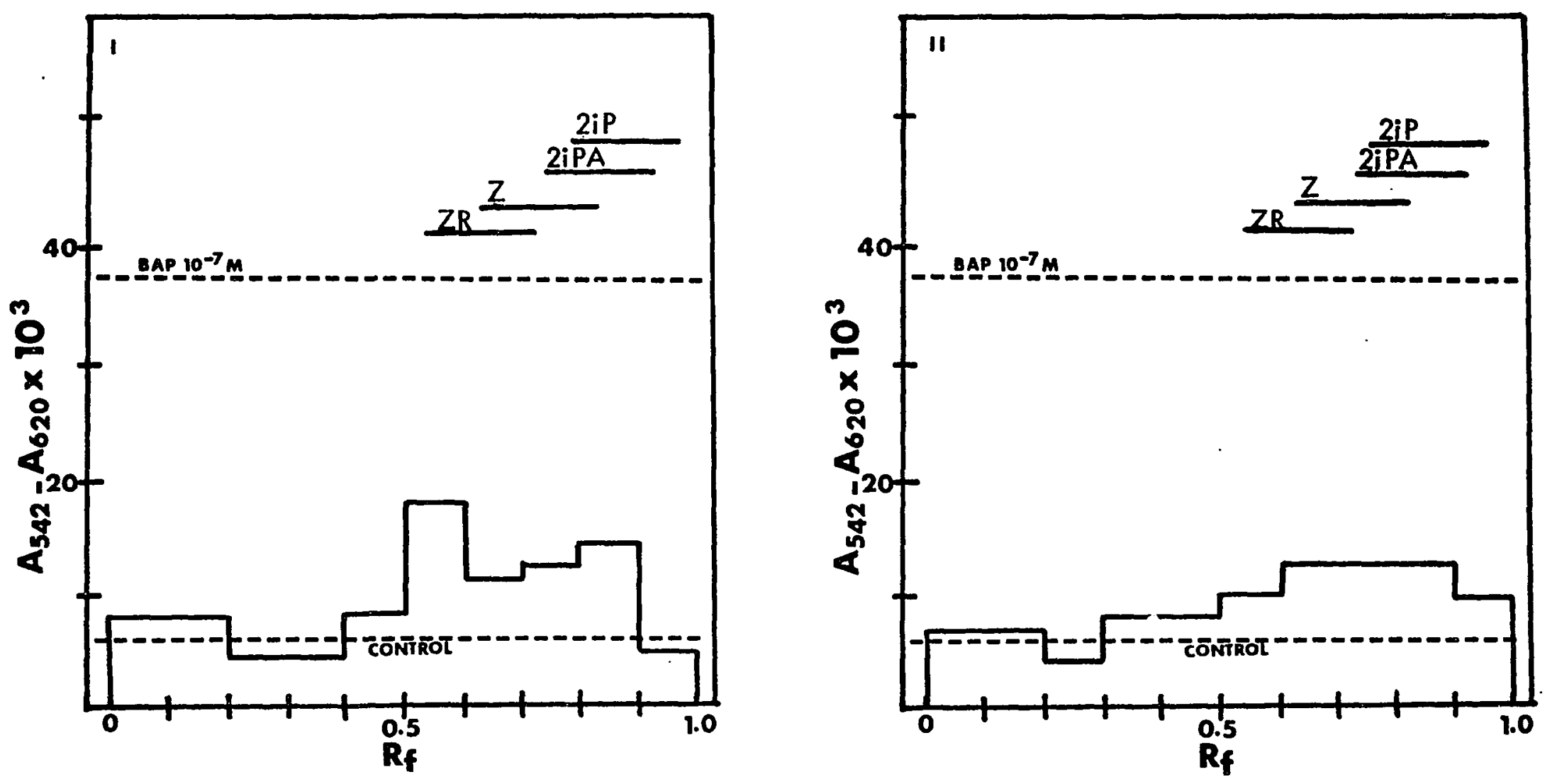

Figure 9. Cytokinin activity in extracts of healthy (I) and infected (II) Douglas-fir first year growth segments, Spring 1977. Amaranthus test assay. $\mathrm{Z}=$ zeatin, $\mathrm{ZR}=$ zeatin riboside, $2 \mathrm{IP}=$ isopentenyladenine, $2 \mathrm{iPA}=$ isopentenyladenosine, $\mathrm{BAP}=$ benzyladenine purine, $\mathrm{A}=$ absorbance, contro1 = untreated cotyledons. 

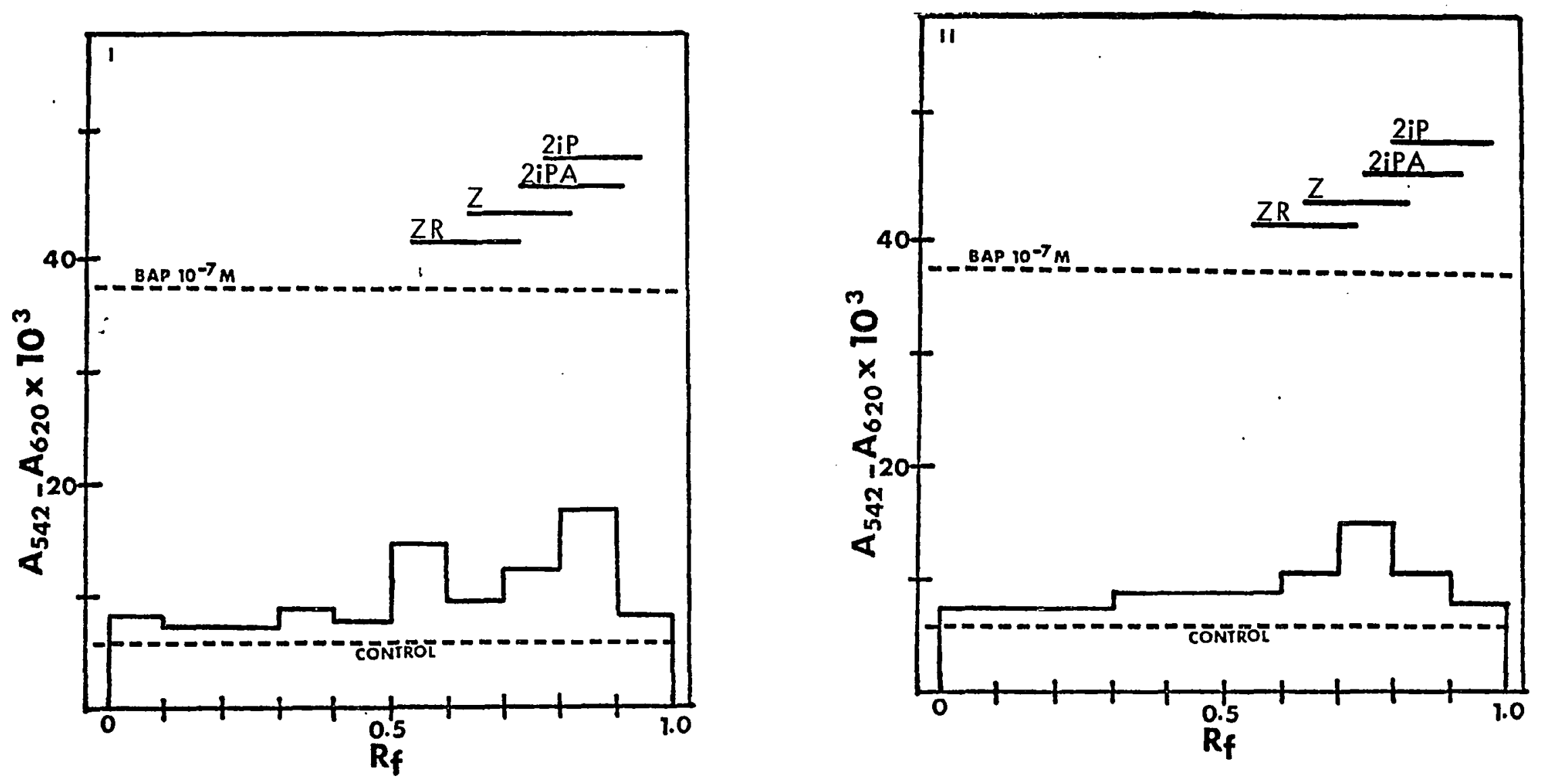

Figure 10. Cytokinin activity in extracts of healthy (I) and infected (II) Douglas-fir first year growth segments, Spring 1978. Amaranthus test assay. $\mathrm{Z}=$ zeatin, $\mathrm{ZR}=$ zeatin riboside, $2 \mathrm{iP}=$ isopentenyladenine, $2 \mathrm{iPA}=$ isopentenyladenosine,

$\mathrm{BAP}$ benzyladenine purine, $\mathrm{A}=$ absorbance, Control = untreated cotyledons. 

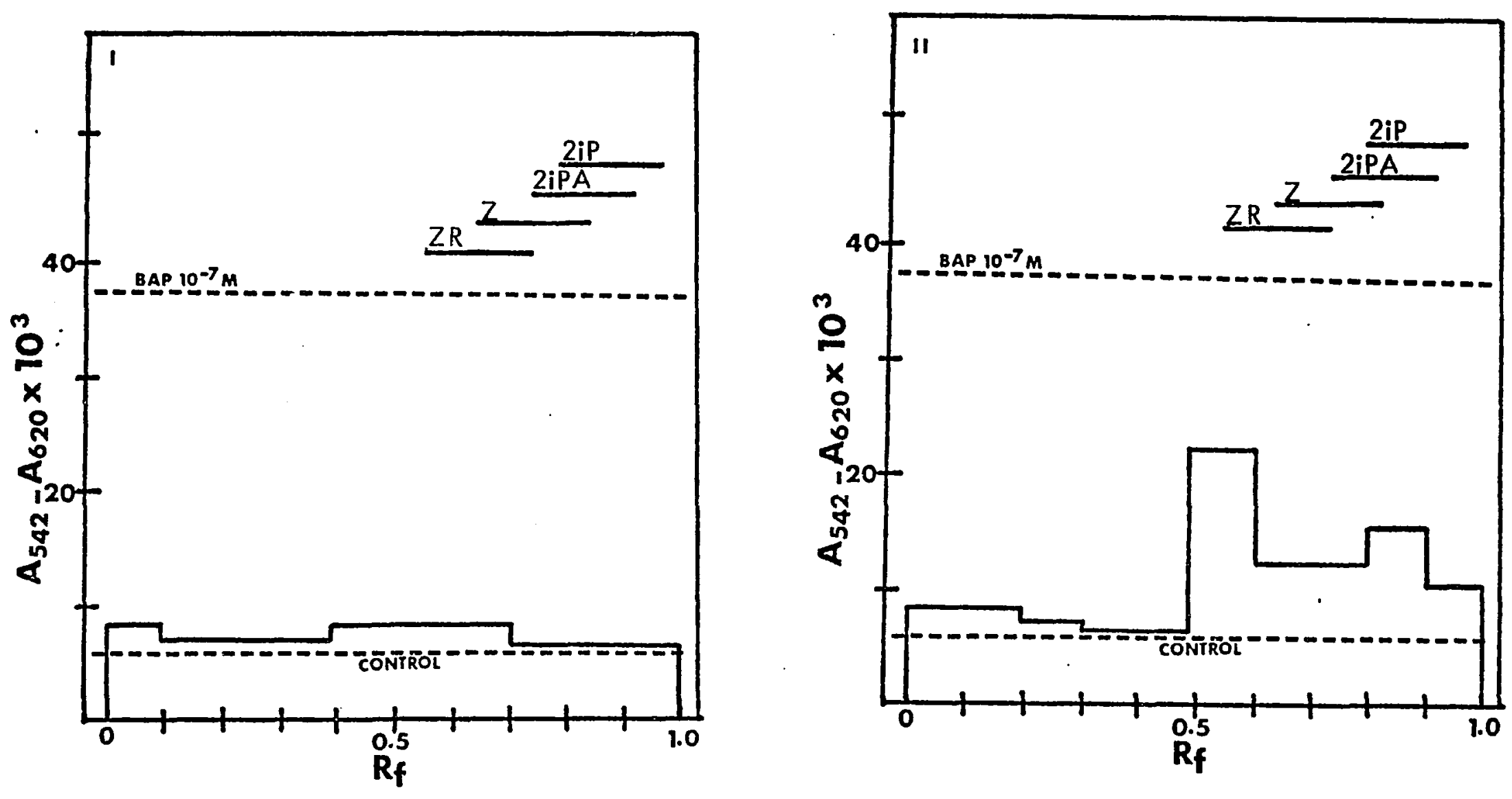

Figure 11. Cytokinin activity in extracts of healthy (I) and infected (II) Douglas-fir fifth year growth segments, Spring 1977. Amaranthus test assay. $\mathrm{Z}=$ zeat $\mathrm{In}, \mathrm{ZR}=$ zeatin riboside, $2 i \mathrm{P}=$ isopentenyladenine, $2 \mathrm{IPA}=$ isopentenyladenosine,

$\mathrm{BAP}=$ benzyladenine purine, $\mathrm{A}=$ absorbance, Control = untreated cotyledons. 

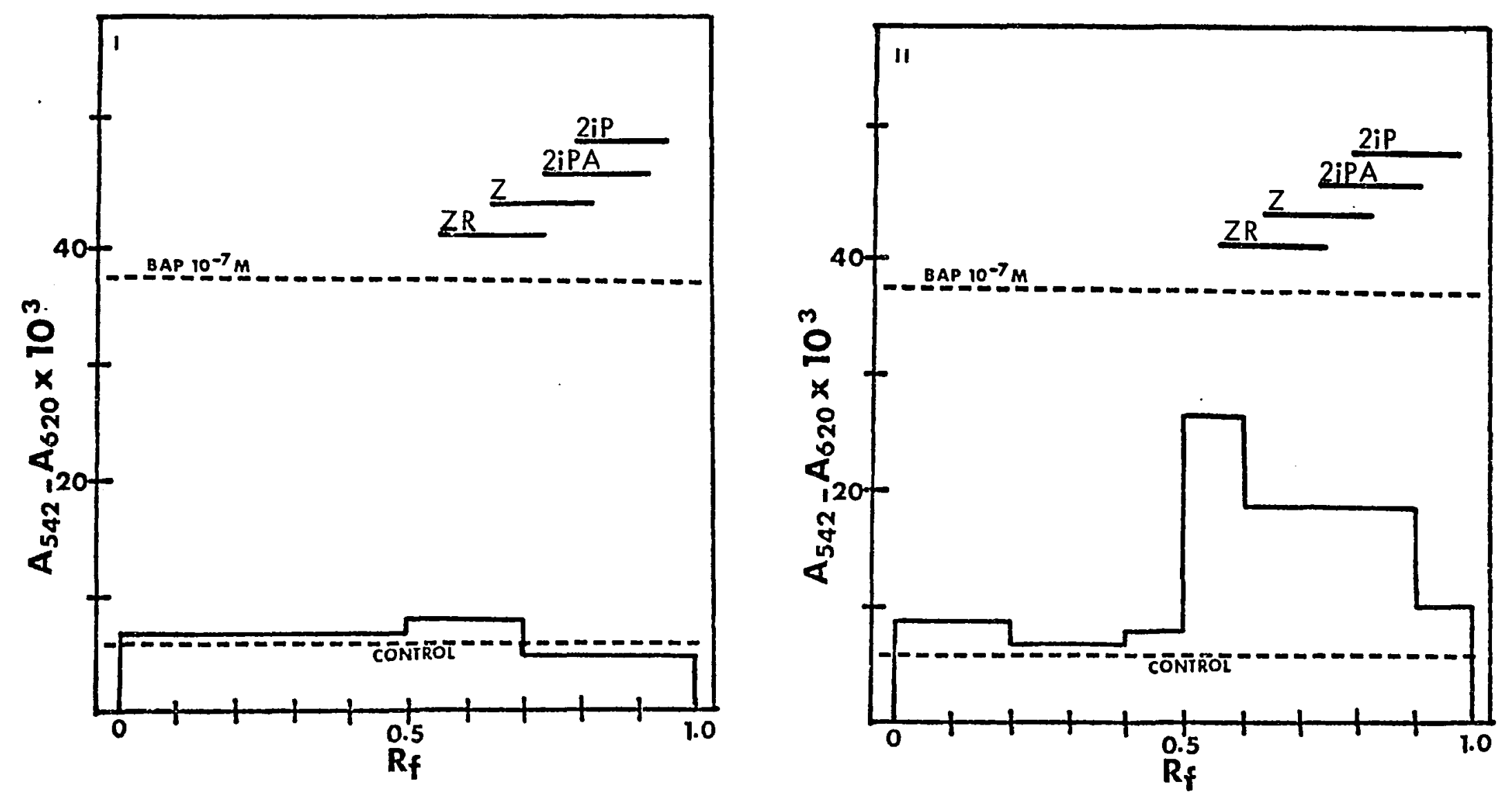

Figure 12. Cytokinin activity in extracts of healthy (I) and infected (II) Douglas-fir fifth year growth segments, Spring 1978. Amaranthus test assay. $\mathrm{Z}=$ zeatin, $\mathrm{ZR}=$ zeatin riboside, $2 i P=$ isopentenyladenine, $2 i P A=$ isopentenyladenoside,

$\mathrm{BAP}=$ benzyladenine purine, $\mathrm{A}=$ absorbance, Control = untreated cotyledons. 

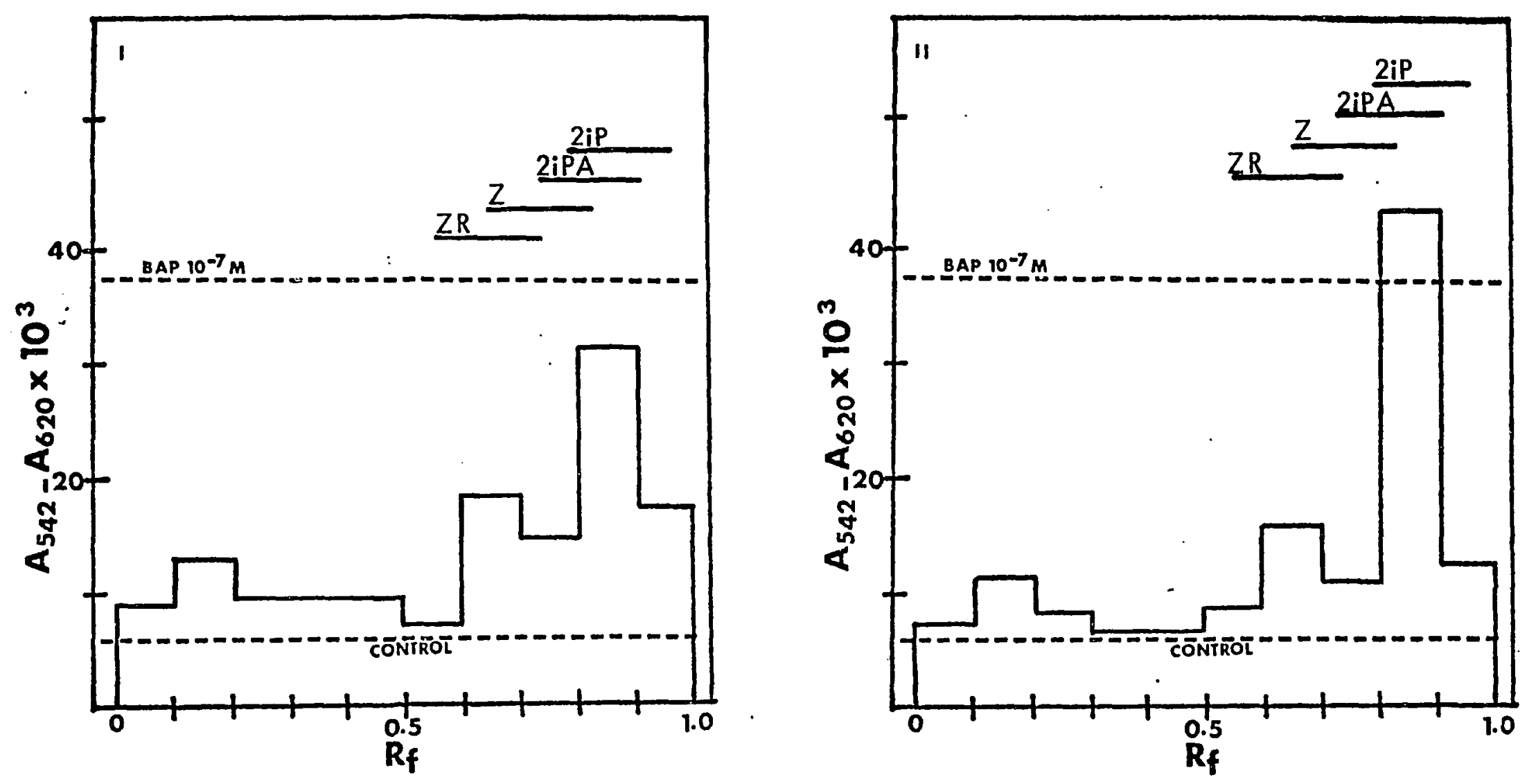

Figure 13. Cytokinin activity in extracts of A. douglasii aerial shoots. Amaranthus test assay. (I) $=$ Spring 1977, (II) $=$ Spring 1978, $\mathrm{Z}=$ zeatin, $\mathrm{ZR}=$ zeatin riboside, $2 \mathrm{IP}=$ isopentenyladenine, 2iPA = isopentenyladenosine, $\mathrm{B} \Lambda \mathrm{P}=$ benzyladenine purine, $A=$ absorbance, Control = untreated cotyledons. 

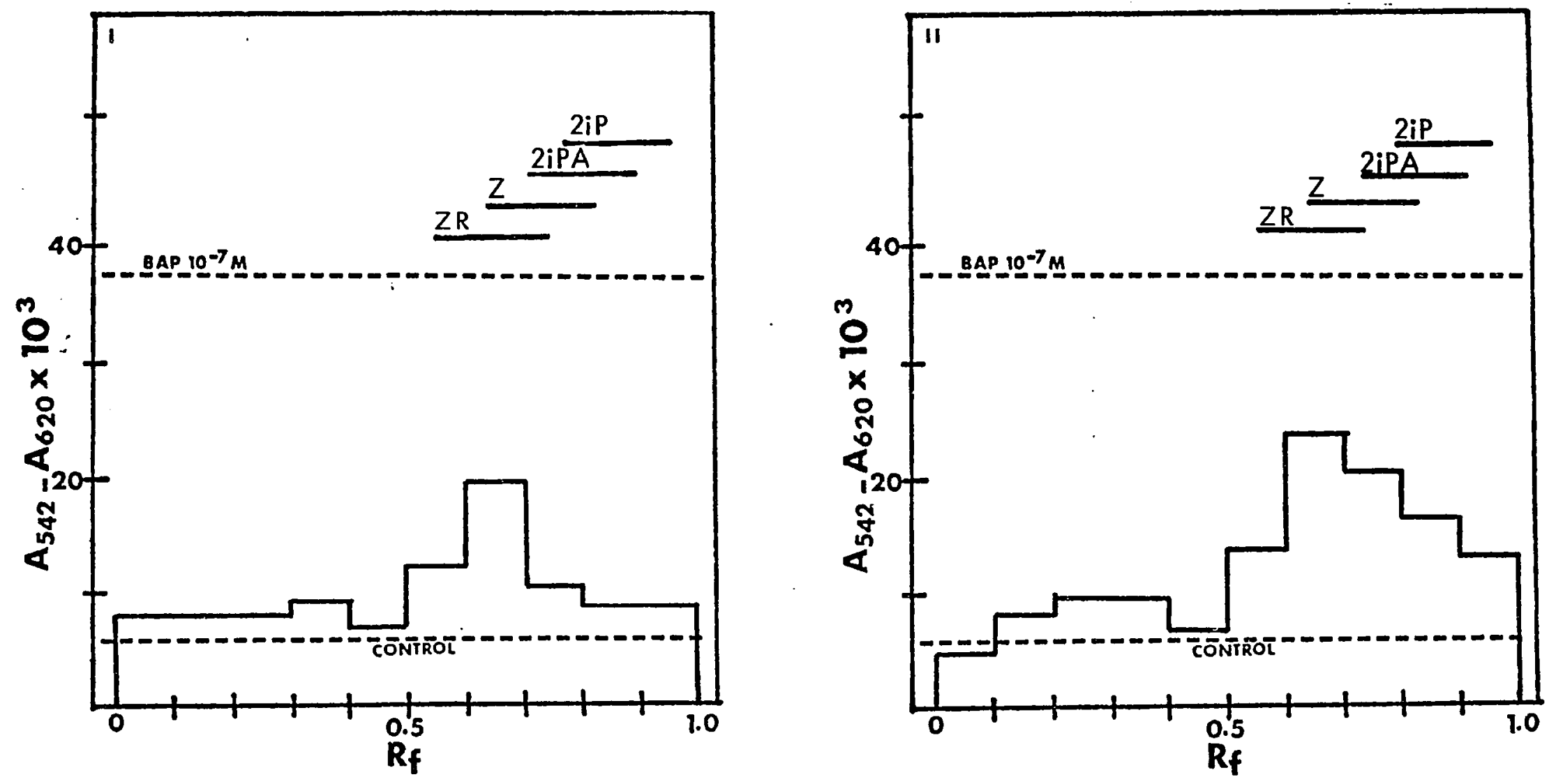

Figure 14. Cytokinin activity in extracts of healthy (I) and infected (II) western hemlock tissue, Spring 1977. Amaranthus test assay. $\mathrm{Z}=$ zeatin, $\mathrm{ZR}=$ zeatin riboside, $2 \mathrm{iP}=$ isopenteny1adenine, $21 \mathrm{PA}=$ isopentenyladenosine, $\mathrm{BAP}=$ benzyladenine purine, $\mathrm{A}=$ absorbance, Control = untreated cotyledons. 

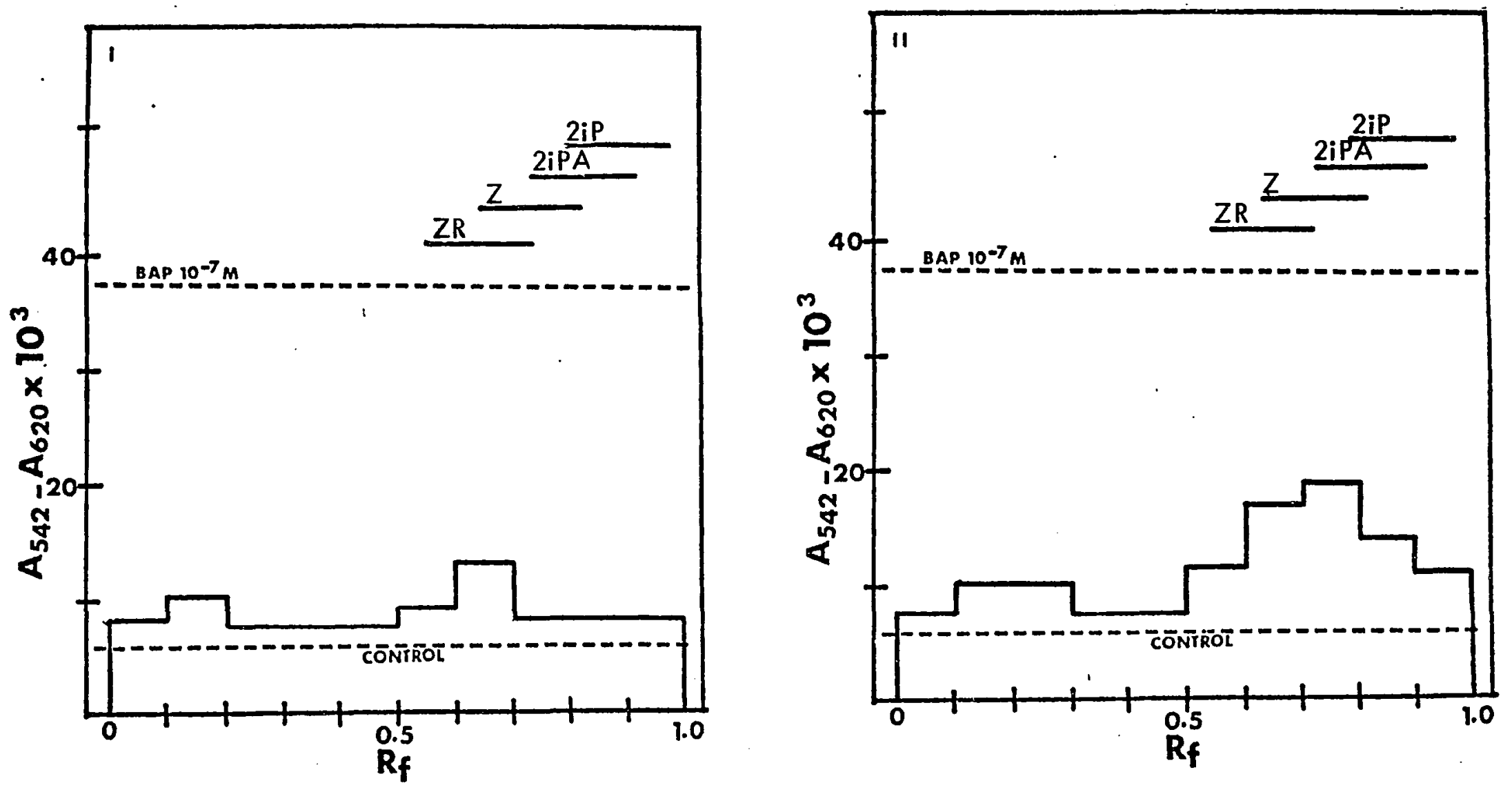

Figure 15. Cytokinin activity in extracts of healthy (I) and infected (II) western hemlock tissue, Spring 1978. Amaranthus test assay. $\mathrm{Z}=$ zeatin, $\mathrm{ZR}=$ zeatin riboside, $21 \mathrm{P}=$ isopenteny1adenine, $21 \mathrm{PA}=1$ sopentenyladenosine, $\mathrm{BAP}=$ benzyladenine purine, $\mathrm{A}=$ absorbance, Control = untreated cotyledons. 

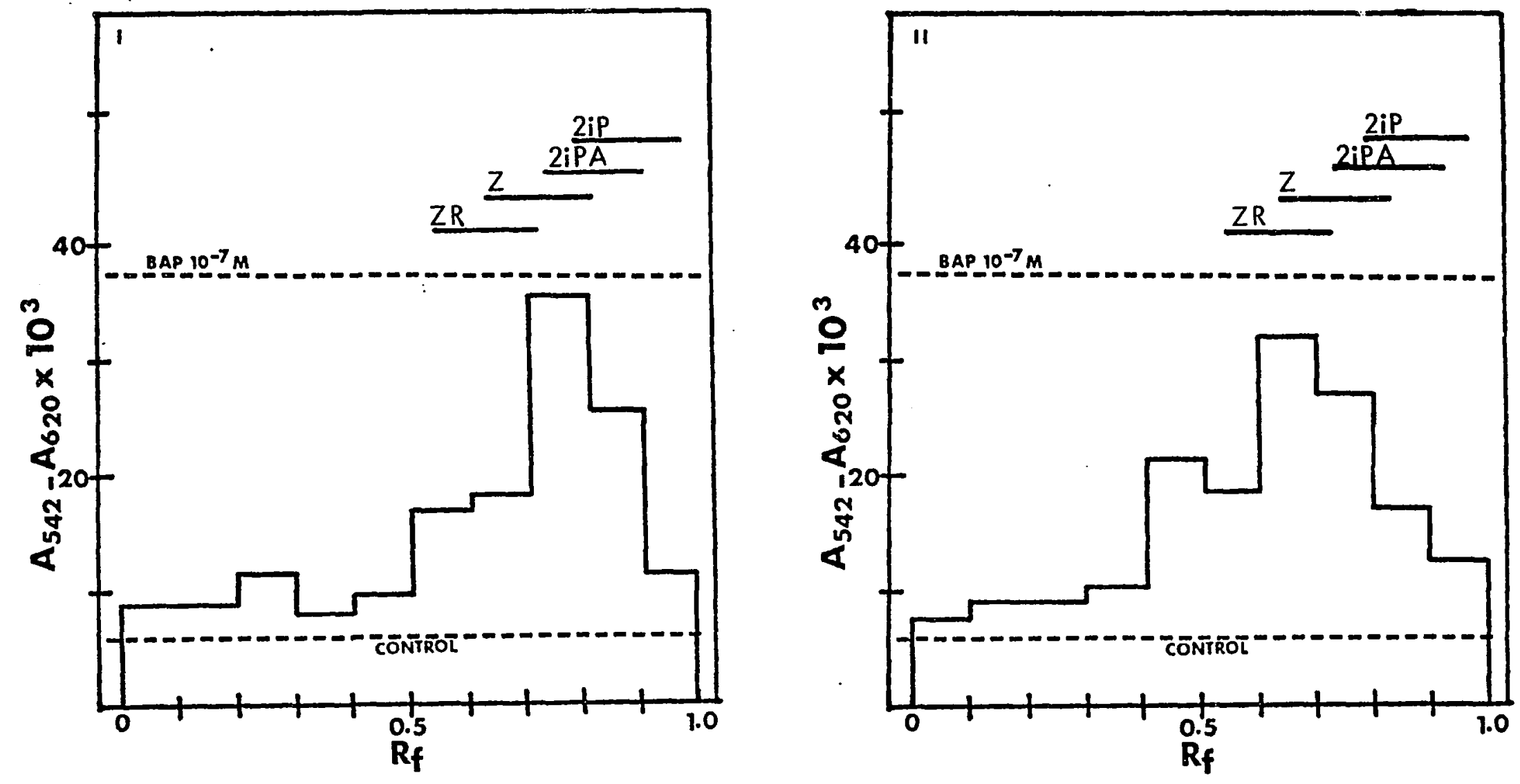

Figure 16. Cytokinin activity in extracts of A. tsugense aerial shoots. Amaranthus test assay. (I) $=$ Spring 1977, (II) = Spring 1978, $\mathrm{Z}=$ zeatin, $\mathrm{ZR}=$ zeatin riboside, $2 \mathrm{iP}=$ isopentenyladenine, $2 \mathrm{iPA}=$ isopentenyladenosine, $\mathrm{BAP}=$ benzyladenine purine, $A=$ absorbance, Control $=$ untreated cotyledons. 

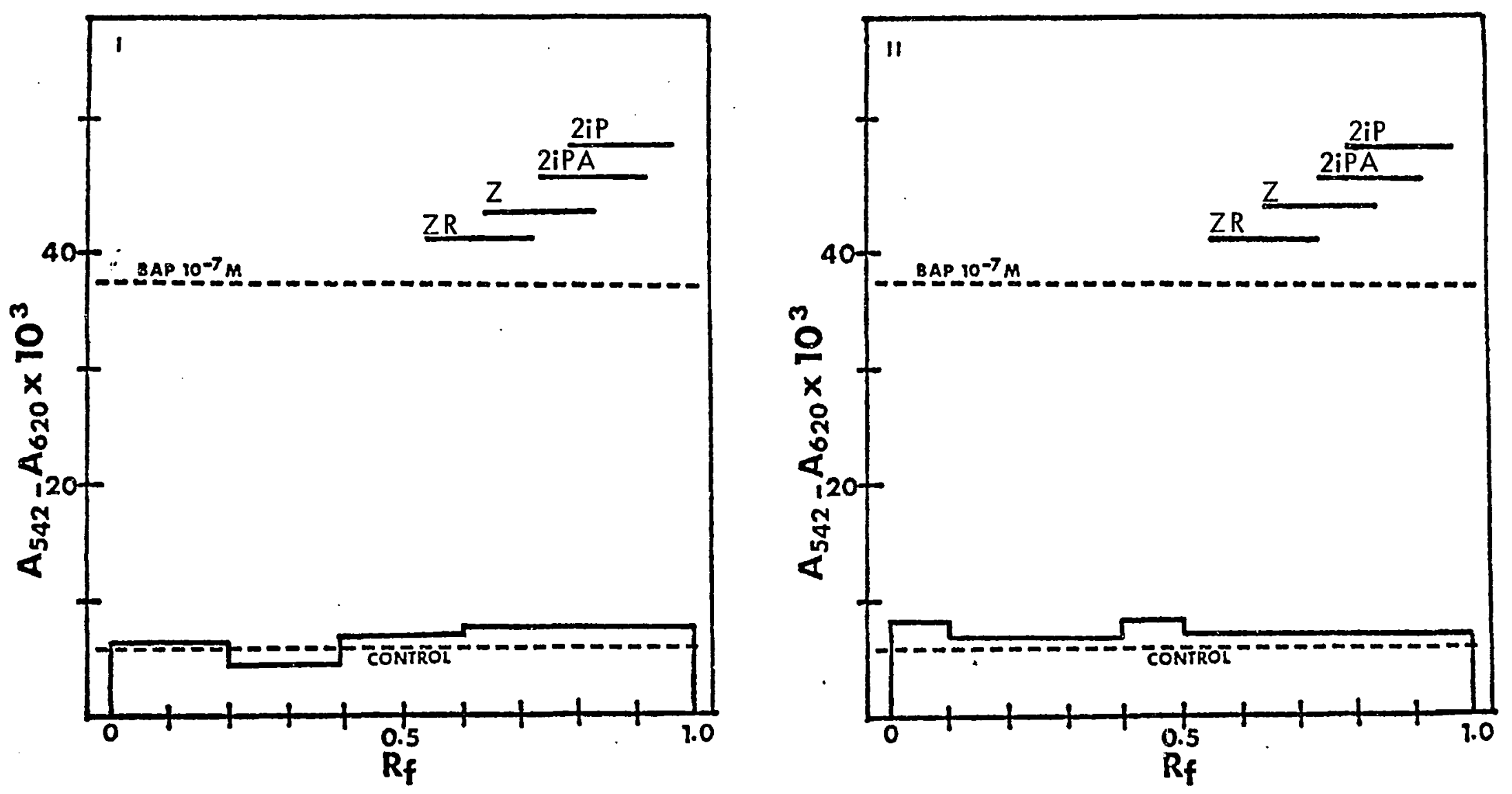

Figure 17. Cytokinin activity of typical winter samples of Douglas-fir (I) and western hemlock (II). Amaranthus test assay. $\mathrm{Z}=$ zeatin, $\mathrm{ZR}=$ zeatin riboside, $21 \mathrm{P}=$ isopentenyladenine, 2IPA = isopentenyladenosine, $\mathrm{BAP}=$ benzyladenine purine, $A=$ absorbance, Contro1 $=$ untreated cotyledons. 


\begin{abstract}
TABLE IV CYTOKININ CONCENTRATION FROM AMARANTHUS BIOASSAY
\end{abstract}

\begin{tabular}{|c|c|c|c|}
\hline \multicolumn{2}{|c|}{ Sample } & \multicolumn{2}{|c|}{$\mu g$ BAP eq./g fresh wt. } \\
\hline $\mathrm{DFSp} 1 \mathrm{H}$ & 1977 & 0.88 & 0.90 \\
\hline DFSp 11 & 1977 & 0.91 & 0.99 \\
\hline DFSp $1 H$ & 1978 & 0.62 & 0.88 \\
\hline DFSp $1 I$ & 1978 & 0.55 & 0.75 \\
\hline DFSp 5 & 1977 & 0.12 & 0.26 \\
\hline DFSp $5 I$ & 1977 & 1.23 & 1.39 \\
\hline $\mathrm{DFSp} 5 \mathrm{H}$ & 1978 & 0.09 & 0.15 \\
\hline DFSp $5 I$ & 1978 & 1.87 & 2.04 \\
\hline DFSp AS & 1977 & 1.69 & 2.10 \\
\hline DESp AS & 1978 & 1.78 & 2.01 \\
\hline WHSp $\mathrm{H}$ & 1977 & 0.87 & 1.12 \\
\hline WHSp I & 1977 & 1.78 & 2.02 \\
\hline WHSp $\mathrm{H}$ & 1978 & 0.49 & 0.73 \\
\hline WHSp I & 1978 & 1.35 & 1.69 \\
\hline WHSp AS & 1977 & 2.32 & 2.58 \\
\hline WHSp AS & 1978 & 2.22 & 2.46 \\
\hline
\end{tabular}


significant, the $\mu g$ BAP equivalents per gram fresh weight for infected material were at least twice that of the corresponding healthy material.

It should be noted that the use of the authentic cytokinin markers in this test is of limited accuracy in determining the actual cytokinin components in the extracts. They were used only to indicate the general Rf range to which authentic standards run. Further analyses to determine the cytokinins present in the samples was thus deemed appropriate and these results are presented in the following sections.

Preparative Thin Layer Chromatography

Preparative TLC was performed as described in the methods section. The Rf zones corresponding to cytokinin standards were scraped from the plates and extracted in $80 \%$ ethanol.

High Performance Thin Layer Chromatography

Aliquots $(0.50 \mu 1)$ of the ethanolic extracts from the preparative TLC were applied as spots to HP-TLC plates and were run in solvent system I (BAW). BAW is effective in separating authentic samples of zeatin and zeatin riboside but standards of $2 \mathrm{iP}$ and $2 \mathrm{iPA}$ show poor separation. The results are presented in Fig. 18 and Table V.

Eleven of the samples showed only a single spot which co-chromatographed with zeatin riboside. Four (DFSpIH, DFSp5I, WHSPI and WHSpAS) showed two spots. The first co-chromatographed with zeatin riboside and the second overlapped more than one Rf zone. The sample from the aerial shoots of A. douglasii also showed two spots but the first spot did not correspond to the Rf zone of any of the standards used and the second overlapped the zones of zeatin, $2 i P$ and 2iPA. 


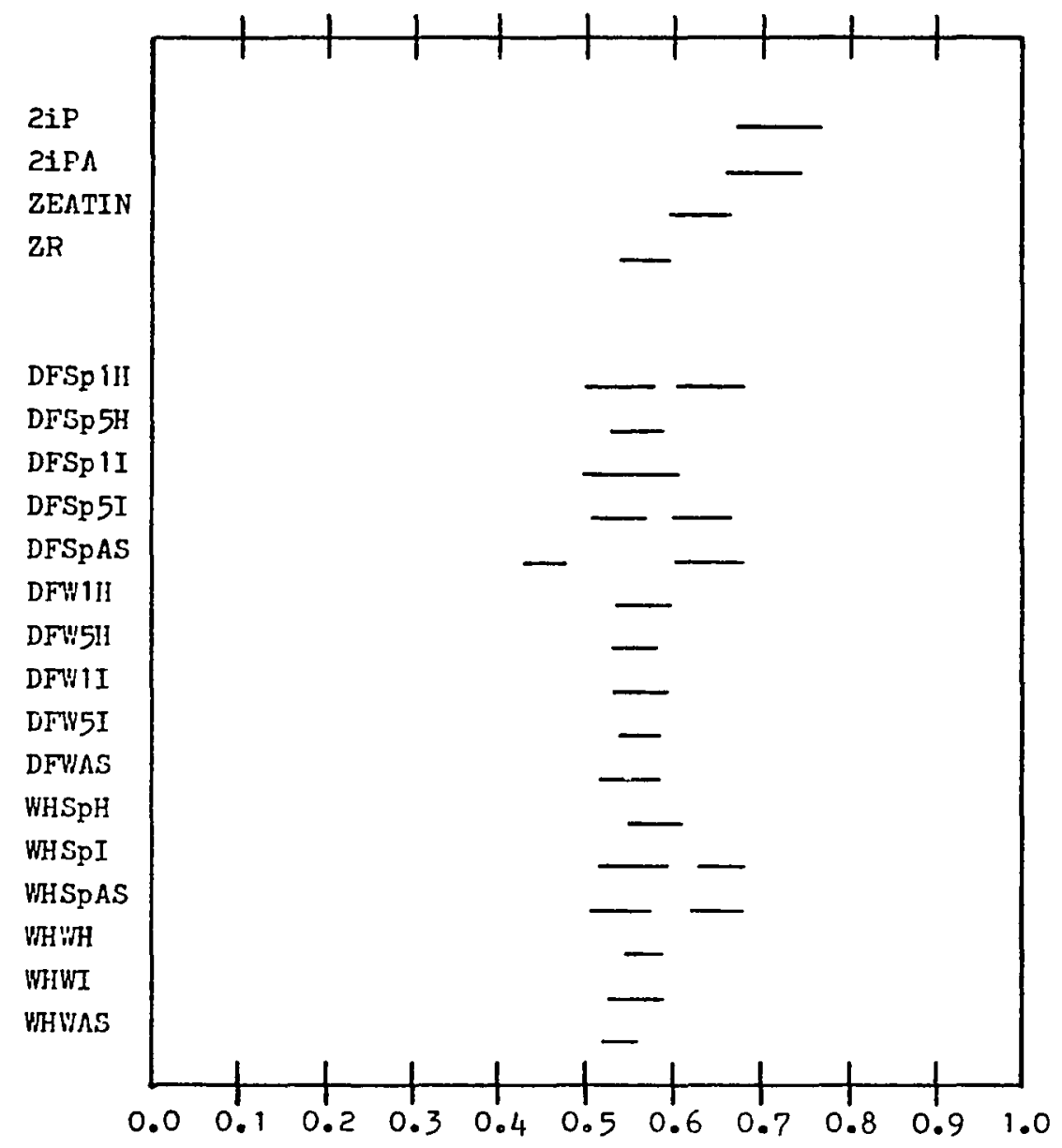

Figure 18. Rf zones for cytokinin standards and tissue extracts run in solvent system I on HP-TLC plates. 
TABLE V

Rf values for samples run in solvent system I

\begin{tabular}{|c|c|c|c|}
\hline Sample & \multicolumn{3}{|c|}{ Rf Zones } \\
\hline $2 i P$ & $(0.67$ & $-0.77)$ & \\
\hline $2 \mathrm{iPA}$ & $(0.66$ & $-0.74)$ & \\
\hline Zeatin & $(0.60$ & $-0.66)$ & \\
\hline Zeatin riboside & $(0.54$ & $-0.60)$ & \\
\hline $\mathrm{DFSp} 1 \mathrm{H}$ & $(0.51$ & $-0.58)$ & $(0.61-0.68)$ \\
\hline DFSp $5 H$ & $(0.53$ & $-0.58)$ & \\
\hline DFSp $1 I$ & $(0.51$ & $-0.61)$ & \\
\hline DFSp 5I & $(0.52$ & $-0.57)$ & $(0.60-0.67)$ \\
\hline DFSp AS & $(0.43$ & $-0.47)$ & $(0.61-0.68)$ \\
\hline DFW $\quad$ IH & $(0.54$ & $-0.61)$ & \\
\hline DFW $\quad 5 \mathrm{H}$ & $(0.53$ & $-0.58)$ & \\
\hline DFW $1 I$ & $(0.53$ & $-0.60)$ & \\
\hline DFW $5 \mathrm{I}$ & $(0.54$ & $-0.58)$ & \\
\hline DFW AS & $(0.52$ & $-0.59)$ & \\
\hline WHSp H & $(0.55$ & $-0.61)$ & \\
\hline WHSp I & $(0.52$ & $-0.60)$ & $(0.63-0.67)$ \\
\hline WHSp AS & $(0.51$ & $-0.58)$ & $(0.62-0.68)$ \\
\hline WHW $\mathrm{H}$ & $(0.54$ & $-0.59)$ & \\
\hline WHW I & $(0.53$ & $-0.59)$ & \\
\hline WHW AS & $(0.52$ & -0.56 & \\
\hline
\end{tabular}


The same samples were run in solvent system II (IAW). This system separates zeatin and zeatin riboside in the reverse order as compared to system I but still gives poor separation between 2 iP and 2 iPA. The results are presented in Fig. 19 and Table VI.

Again, eleven samples showed a single spot that co-chromatographed with zeatin riboside. The same four samples as in system I showed two spots. The first co-chromatographed with zeatin riboside and the second overlapped more than one Rf zone. The DFSpAS sample showed two spots, the first did not correspond to any of the standards used and the second overlapped several Rf zones.

The above extracts and standards were subjected to HP-TLC in solvent system III (BW) a system which provides good separation of 2 iP and 2iPA with some overlaps of the Rf zones of zeatin and zeatin riboside. The results are presented in Fig. 20 and Table VII.

Twelve of the samples showed a single spot that overlapped the Rf zones of zeatin and zeatin riboside. Three (DFSPSI, WHSpI and WHSpAS) samples revealed two spots. The first overlapped with zeatin and zeatin riboside while the second spot from the DFSPSI and the WHSPI co-chromatographed with 2iPA and the second spot from the WHSpAS overlapped the zones of zeatin riboside and 2 iPA.

One sample (DFSpAS) revealed three spots. The first had an Rf zone that did not correspond with the Rf zone of the standards. The second overlapped the zones of zeatin and zeatin riboside while the third cochromatographed with 2 iPA.

In a fourth HP-TLC analysis the trimethyl silyl derivatives of the standards and the extracts were run in solvent system IV (CM). This 


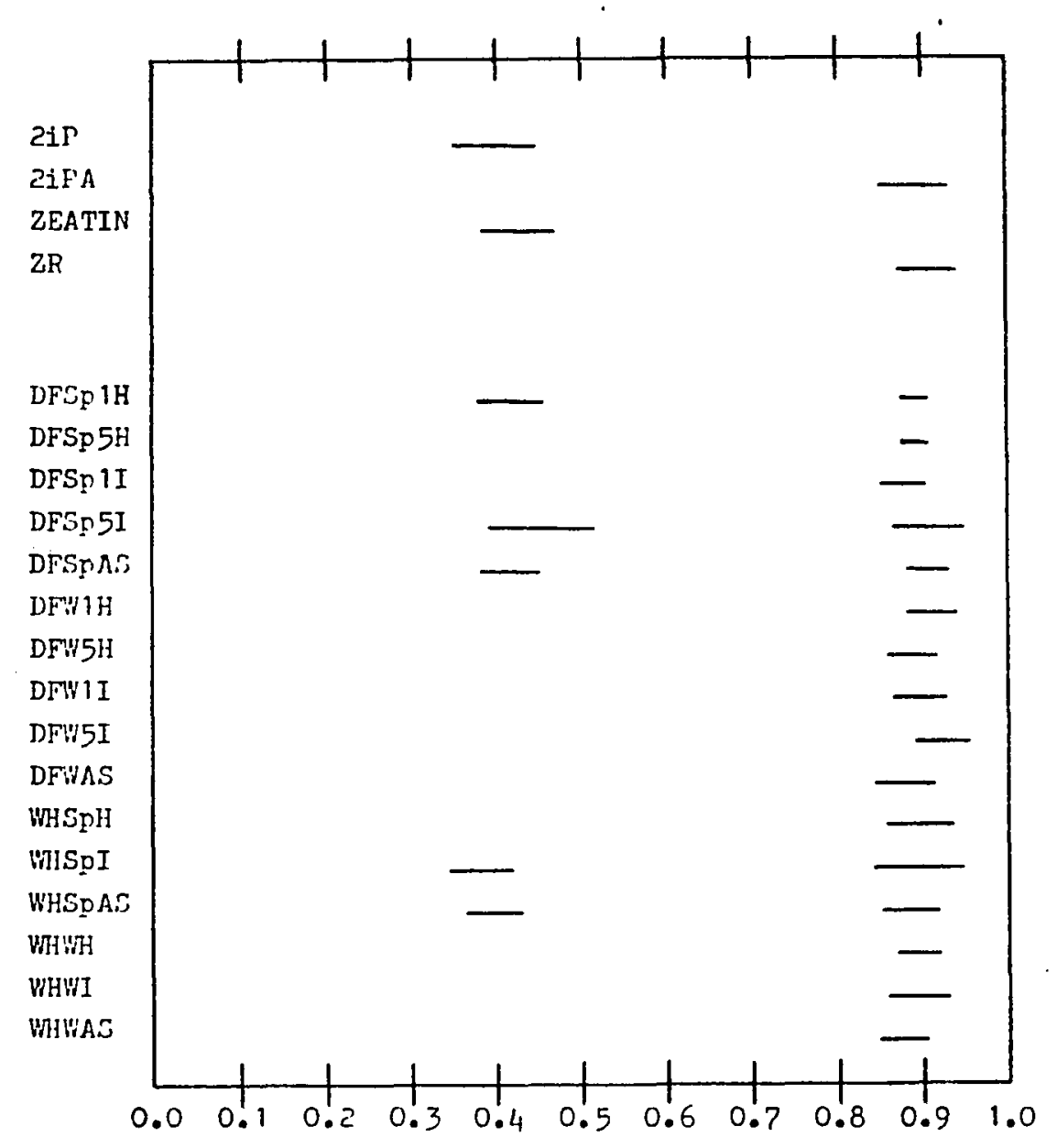

Figure 19. Rf zones for cytokinin standards and tissue extracts run in solvent system II on HP-TLC plates. 
TABLE VI

Rf values for samples run in solvent system II

\begin{tabular}{|c|c|c|c|}
\hline Sample & \multicolumn{3}{|c|}{ Rf Zones } \\
\hline $2 i P$ & $(0.59-$ & $-0.65)$ & \\
\hline $2 \mathrm{iPA}$ & $(0.58-$ & $-0.69)$ & \\
\hline Zeatin & $(0.49-$ & $-0.53)$ & \\
\hline Zeatin riboside & $(0.53-$ & $-0.59)$ & \\
\hline DFSp $1 \mathrm{H}$ & $(0.49-$ & $-0.52)$ & $(0.54-0.58)$ \\
\hline DFSp $5 \mathrm{H}$ & $(0.54-$ & $-0.57)$ & \\
\hline DFSp $1 \mathrm{I}$ & $(0.52-$ & $-0.58)$ & \\
\hline DFSp $5 I$ & $(0.46-$ & $-0.52)$ & $(0.54-0.60)$ \\
\hline DFSp AS & $(0.42-$ & $-0.50)$ & $(0.58-0.65)$ \\
\hline DFW IH & $(0.52-$ & $-0.57)$ & \\
\hline $\mathrm{DFW} 5 \mathrm{H}$ & $(0.52-$ & $-0.58)$ & \\
\hline DFW $1 \mathrm{I}$ & $(0.53-$ & $-0.57)$ & \\
\hline DFW 5I & $(0.53-$ & $-0.58)$ & \\
\hline DFW AS & $(0.52-$ & $-0.59)$ & \\
\hline WHSp $\mathrm{H}$ & $(0.54-$ & $-0.60)$ & \\
\hline WHSp I & $(0.53-$ & $-0.57)$ & $(0.63-0.68)$ \\
\hline WHSp AS & $(0.48-$ & $-0.51)$ & $(0.54-0.65)$ \\
\hline WHW $\mathrm{H}$ & $(0.53-$ & $-0.57)$ & \\
\hline WHW I & $(0.54$ & $-0.58)$ & \\
\hline WHW AS & $(0.54-$ & $-0.68)$ & \\
\hline
\end{tabular}




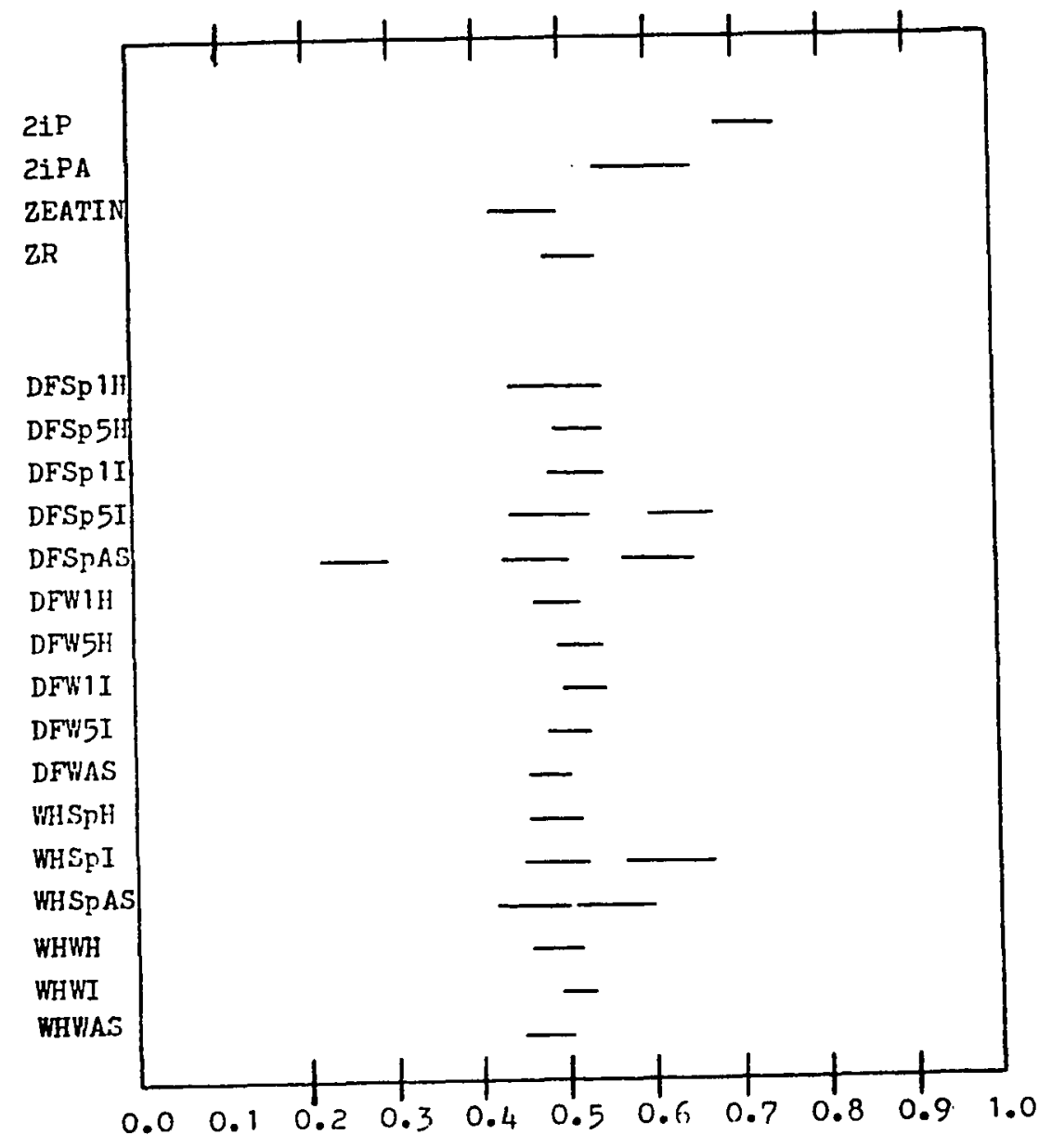

Figure 20. Rf zones for cytokinin standards and tissue extracts run in solvent system III on HP-TLC plates. 
TABLE VII

Rf values for samples run in solvent system III

Sample

Rf Zones

\begin{tabular}{ll} 
2iP & $(0.68-0.75)$ \\
2iPA & $(0.54-0.66)$ \\
Zeatin & $(0.41-0.50)$ \\
Zeatin riboside & $(0.48-0.54)$ \\
\hline DFSp 1H & $(0.44-0.55)$ \\
DFSp 5H & $(0.49-0.55)$ \\
DFSp 1I & $(0.48-0.55)$ \\
DFSp 5I & $(0.44-0.53) \quad(0.60-0.66)$ \\
DFSP AS $(0.22-0.29)$ & $(0.43-0.51) \quad(0.57-0.65)$ \\
DFW IH & $(0.47-0.52)$ \\
DFW 5H & $(0.49-0.54)$ \\
DFW II & $(0.50-0.54)$ \\
DFW 5I & $(0.48-0.53)$ \\
DFW AS & $(0.46-0.51)$ \\
WHSP H & $(0.46-0.52)$ \\
WHSP I & $(0.45-0.53) \quad(0.57-0.67)$ \\
WHW AS & $(0.42-0.51) \quad(0.51-0.60)$ \\
WHW H & $(0.46-0.52)$ \\
WHW I & $(0.49-0.53)$ \\
WHW AS & $(0.45-0.51)$ \\
&
\end{tabular}


system proved to be advantageous in that the TMS derivatives of the ribosides were separated from the corresponding non-ribosides by a greater margin. The results are presented in Fig. 21 and Table viII.

Eleven of the samples showed a single spot which overlapped with zeatin riboside and 21PA. Five samples (DFSplH, DFSp5I, DFSpAS, WHSPI, and VHSPAS) revealed two spots. The first overlapped the Rf zones of zeatin and $21 P$ and the second overlapped the zones of zeatin riboside and $2 \mathrm{IPA}$.

\section{Gas-LIquid Chromatography}

The TMS derivatives of the Spring and Winter samples (1976-1977 and 1977-1978) were subjected to GLC. All of the standards and a11 of the tissue samples were spiked with pyrene as an internal standard from which relative retention times were determined. The results are presented in Tables $I X$ and $X$.

The extracts of Winter samples of both the hosts and the dwarf mistletoes consistently revealed only a single small peak with a relative retention time corresponding to that of zeatin riboside. A number of other peaks were recorded but these did not correspond to any of the known standards.

Both the infected and uninfected Spring samples from Douglas-fir and western hemlock showed from three to seven peaks but only those that relative retention times the same as the standards will be dealt with. The uninfected Spring collected first growth segments from Douglas-fir had two peaks that had the same relative retention time as zeatin and zeatin riboside. Uninfected fifth growth segments from the aforemen- 


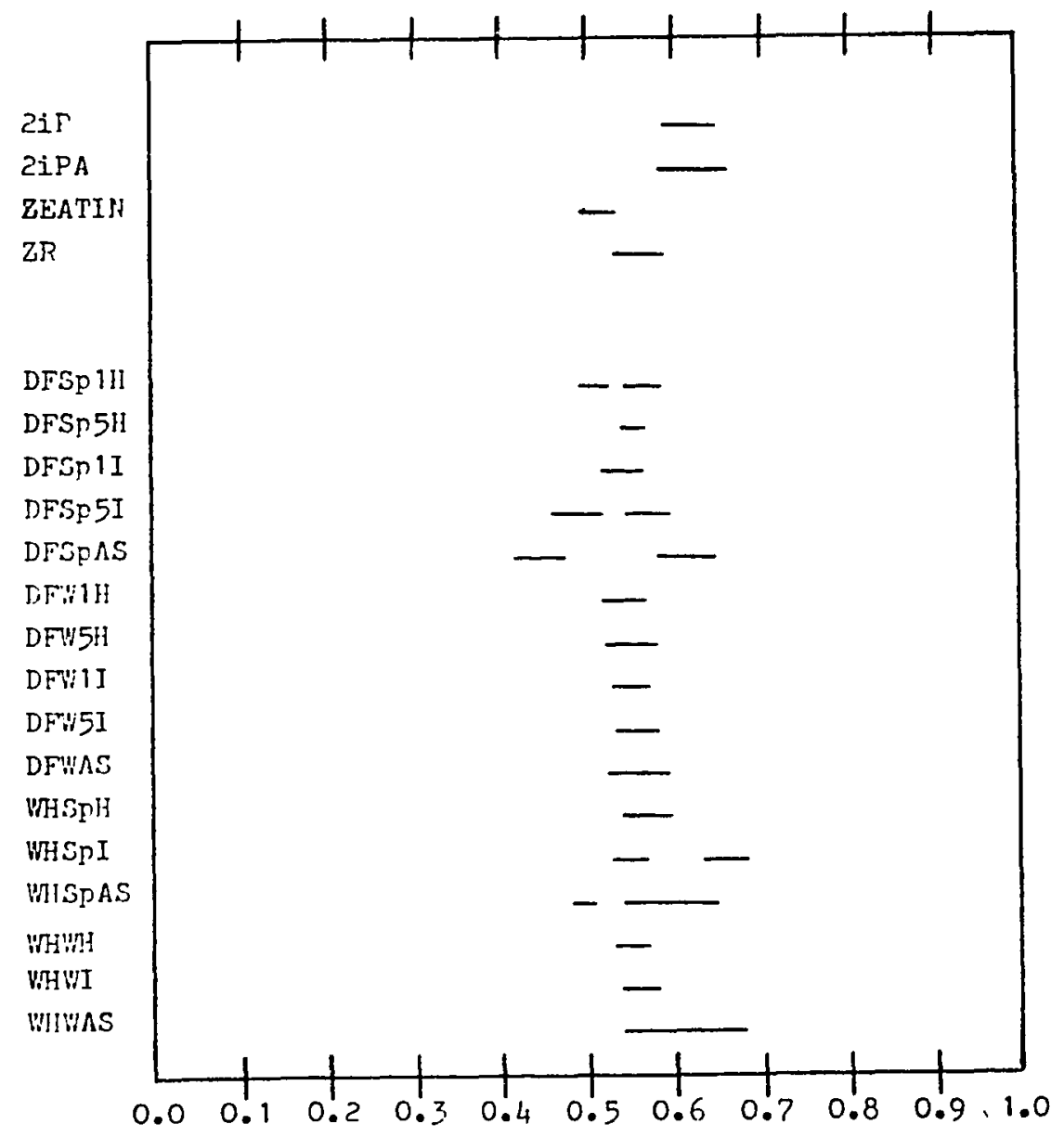

Figure 21. Rf zones for cytokinin standards and tissue extracts run in solvent system IV on HP-TLC plates. 
TABLE VIII

Rf values for samples run in solvent system IV

\begin{tabular}{|c|c|c|c|}
\hline Sample & \multicolumn{3}{|c|}{ Rf Zones } \\
\hline $2 i P$ & $(0.35$ & $-0.45)$ & \\
\hline $2 \mathrm{iPA}$ & $(0.85$ & $-0.93)$ & \\
\hline Zeatin & $(0.38$ & $-0.47)$ & \\
\hline Zeatin riboside & $(0.87$ & $-0.94)$ & \\
\hline DFSp $1 \mathrm{H}$ & 10.38 & -0.46 & $(0.88-0.91)$ \\
\hline DFSp $5 \mathrm{H}$ & $(0.88$ & $-0.91)$ & \\
\hline DFSp $1 I$ & $(0.85$ & $-0.91)$ & \\
\hline DFSp 5I & $(0.39$ & $-0.52)$ & $(0.86-0.95)$ \\
\hline DFSp AS & $(0.38$ & $-0.45)$ & $(0.88-0.93)$ \\
\hline DFW $1 \mathrm{H}$ & $(0.88$ & $-0.94)$ & \\
\hline $\mathrm{DFW} 5 \mathrm{H}$ & $(0.86$ & $-0.92)$ & \\
\hline DFW $1 I$ & $(0.87$ & $-0.93)$ & \\
\hline DFW $5 I$ & $(0.89$ & $-0.96)$ & \\
\hline DFW AS & $(0.84$ & $-0.92)$ & \\
\hline WHSp $\mathrm{H}$ & $(0.86$ & $-0.94)$ & \\
\hline WHSp I & $(0.34$ & $-0.52)$ & $(0.84-0.95)$ \\
\hline WHW $\mathrm{H}$ & $(0.87$ & $-0.92)$ & \\
\hline WHW I & $(0.86$ & $-0.93)$ & \\
\hline WHW AS & $(0.85$ & -0.91 & \\
\hline
\end{tabular}


tioned host had only a single peak which had the same relative retention time as zeatin riboside.

The first growth segment from the infected Spring Douglas-fir also, showed only a single identifiable peak that had the same relative retention time as zeatin riboside. The fifth growth segment from this same host showed three identifiable peaks which had relative retention times that corresponded with zeatin, zeatin riboside and 2iPA. The aerial shoots from the Spring A. douglassi showed only two identifiable peaks and these had relative retention times the same as zeatin and 2 iPA. Uninfected tissue from Spring collected western hemlock had a single identifiable peak which had the same relative retention time as zeatin riboside. The infected samples of Spring collected western hemlock had three identifiable peaks that had the same relative retention times as zeatin, zeatin riboside and 2iPA. Similar results were obtained from the extracts of the aerial shoots of $\underline{A}$. tsugense.

TABLE IX

Relative Retention Times for Cytokinin Standards

Standard

Relative Retention Time

Pyrene $\quad 1.00$

2 iP

1.25

Zeatin

1.51

2iPA

1.62

Zeatin Riboside

1.80 
TABLE X

GLC Analysis of Extractions from Procedure II

\begin{tabular}{|c|c|c|c|c|}
\hline Sample & $2 i P$ & $2 i P A$ & Zeatin & $\begin{array}{l}\text { Zeatin } \\
\text { Riboside }\end{array}$ \\
\hline DFSp $1 \mathrm{H}$ & - & - & $+(1.49) *$ & $+(1.81) *$ \\
\hline DFSp $5 \mathrm{H}$ & - & - & - & $+(1.81) *$ \\
\hline DFSp $1 I$ & - & - & - & $+(1.82) *$ \\
\hline DFSp $5 I$ & - & $+(1.61) *$ & $+(1.49) *$ & $+(1.80) *$ \\
\hline DFSp AS & - & $+(1.60) *$ & $+(1.52) *$ & - \\
\hline DFW 1H & - & - & - & $+(1.78) *$ \\
\hline DFW $5 \mathrm{H}$ & - & - & - & $+(1.82) *$ \\
\hline DFW $1 I$ & - & - & - & $+(1.80) *$ \\
\hline DFW 5I & - & - & - & $+(1.81) *$ \\
\hline DFW AS & - & - & - & $+(1.83) *$ \\
\hline WHSp $\mathrm{H}$ & - & - & - & $+(1.81) *$ \\
\hline WHSp I & - & $+(1.61) *$ & $+(1.50) *$ & $+(1.80) *$ \\
\hline WHSp AS & - & $+(1.63) *$ & $+(1.51) *$ & $+(1.80) *$ \\
\hline WHW H & - & - & - & $+(1.78) *$ \\
\hline WHW I & - & - & - & $+(1.81) *$ \\
\hline WHW AS & - & - & - & $+(1.81) *$ \\
\hline
\end{tabular}

*Values in parentheses indicate relative retention time. 
Quantification of the cytokinin components of Spring samples was carried out by the internal standard method. The results are presented in Table XI. The accuracy of these values is questionable because of the difficulties encountered in determining peak areas. Most of these difficulties arose from the long temperature program employed, which tends to broaden peak widths and make accurate determination of the baseline impossible. A number of peaks also overlapped unidentifiable peaks.

Although these results indicate the same pattern of cytokinin concentrations as Amaranthus bioassay, direct comparisons cannot be made. The cytokinin concentrations shown from the Amaranthus test are $\mu \mathrm{g}$ equivalents of the synthetic standard BAP and the actual concentrations of naturally occurring cytokinins will vary with their biological activity. Thomas (1975) has indicated that the sensitivity of the Amaranthus test is on the order of 1.5 to 20 times greater than that of GLC, depending on the particular cytokinin tested. 
TABLE XI

Cytokinin Concentration of Spring Samples

as Determined by GLC

\begin{tabular}{|c|c|c|c|c|c|}
\hline \multirow[b]{2}{*}{ Sample } & \multicolumn{5}{|c|}{ CONCENTRATION ( $\mu \mathrm{g} / \mathrm{g}$ fresh wt.) } \\
\hline & $2 i p$ & Zeatin & $2 \mathrm{iPA}$ & Zeatin Riboside & TOTAL \\
\hline DFSp $1 \mathrm{H}$ & - & -- & -- & 0.15 & 0.15 \\
\hline DFSp $5 H$ & - & 0.23 & -- & 0.11 & 0.34 \\
\hline DFSp $1 I$ & - & -- & -- & 0.14 & 0.14 \\
\hline DFSp $5 I$ & - & 0.82 & 0.16 & 0.35 & 1.33 \\
\hline DFSp AS & - & 1.31 & 0.55 & -- & 1.90 \\
\hline WHSp H & - & -- & -- & 0.53 & 0.53 \\
\hline WHSp I & & 0.86 & 0.12 & 0.23 & 1.21 \\
\hline WHSp AS & - & 1.39 & 0.26 & 0.33 & 1.98 \\
\hline
\end{tabular}




\section{DISCUSSION AND CONCLUSIONS}

\section{Seasonal Fluctuation}

The results presented indicate that there is a seasonal fluctuation in cytokinins present in both dwarf mistletoes and their hosts. My data show a marked increase in cytokinin activity during the period just prior to bud break in the Spring with a sharp drop off in activity after this season. The pumpkin seed cotyledon bioassay and the Amaranthus bioassay are both consistent in demonstrating this fact. These results are in agreement with those reported by Alvim et. al. (1976) for studies conducted on seasonal variation of cytokinins in Salix viminalis. They also are in agreement with the results of Hewett and Wareing (1973) concerning cytokinin activity in the buds and woody sap of Populus $\times$ robusta during chilling and bud break.

Some seasonal variation in the makeup of the cytokinins is also shown to occur. This variation in cytokinin content is much greater in the Infected tissue and the aerial shoots of the dwarf mistletoes than in the uninfected tissue. Both the HP-TLC and the GLC analyses indicate that the major cytokinin component of both infected and uninfected tissue is zeatin riboside. This cytokinin is present in most of the samples on a year-round basis. The only exception being the Spring aerial shoots of A. douglasii. The other cytokinins examined (zeatin and 2iPA) are found during the Spring but were not detectable in the other seasons. The use of larger tissue samples might show these substances to be present but in reduced amounts. 


\section{Infected vs. Uninfected Material}

The foregoing results show that there is a large difference in cytokinin activity between infected and uninfected host tissue in both Douglas-fir and western hemlock during the Spring just prior to bud break. In Douglas-fir, the outstanding difference is between the fifth growth segment samples where there is both a difference in activity as determined by bioassay and in the cytokinins detected. The bioassays show that cytokinin activity in the infected fifth growth segments is more than twice that found in the corresponding uninfected material. Also, both HP-TLC and GLC analysis show only a single cytokinin (zeatin riboside) to be present in the uninfected material whereas, there are three detectable cytokinins in the infected material (2iPA, zeatin and zeatin riboside).

The first growth segment samples of Spring Douglas-fir are interesting in that there is no significant difference in cytokinin activity between healthy and infected materials. However, the healthy material contained two cytokinins (zeatin and zeatin riboside) whereas only zeatin riboside was detectable in the infected material.

The western hemlock tissues tested showed similar results to those found in the Douglas-fir systems. The infected tissue, taken from the areas of swelling, showed greater cytokinin activity than the corresponding uninfected tissue. The cytokinin identified by GLC and HP-TLC in the infected tissue were the same as those found in the fifth growth segments from Douglas-fir. Zeatin riboside was the only identifiable cytokinin from the uninfected tissues. First year growth segments from 
western hemlock were not tested so no comparison can be made.

It is of interest to note that zeatin riboside was found to be present in all of the tissue samples, with the exception of the Spring aerial shoots of $\underline{A}$. douglasii. This is somewhat puzzling and cannot be explained at this time. However, it should also be noted that the HPTLC analysis of this tissue showed a spot in solvent. systems I, II and III that had Rf values always somewhat lower than the standards used. It is possible that this spot represents one of the cytokinin glycosides which have recently been reported as occurring naturally in a number of plants (VanStaden 1976; Van Staden 1977; Davey and VanStaden 1977; Dimalla et. al. 1977).

It should also be noted that 2iPA was found only in the aerial shoots of dwarf mistletoes or in the infected host material. This suggests that 2iPA is produced only by the dwarf mistletoe but this cannot be proven without separation and "in vitro" culture of the parasite including the endophytic system. The possibility remains that this substance is produced by the host in response to the parasite and is translocated to the aerial shoots via the endophytic system.

As determined by the Amaranthus bioassay and GLC, the aerial shoots of A. douglasii had 5 to 10 times the concentration of cytokinins than the healthy fifth growth segments. A. tsugense aerial shoots had 2 to 3.5 times as much cytokinin as the healthy material.

Two cytokinins, zeatin and 2iPA, were identified by HP-TLC and GLC as being present in the aerial shoots of $\underline{A}$. douglasii. Both of these cytokinins were also present in the infected host tissue along with zeatin riboside which could not be found in the aerial shoots. Uninfected 
tissue from Douglas-fir contained zeatin and zeatin riboside.

The Spring aerial shoots of $\underline{A}$. tsugense contained three cytokinins: zeatin, zeatin riboside and 2iPA. A11 three of these cytokinins were present in the infected tissue whereas, only zeatin riboside was identifed from the uninfected tissue.

Analysis of Winter aerial shoots from both species showed only zeatin riboside to be present during this season.

The foregoing provides several possible clues concerning the hostparasite physiological relationship. Hull and Leonard (1964a and 1964b) and Greenham and Leonard (1965) showed dwarf mistletoes to be dependent upon their hosts for their nutritional needs. Their work, using labeled carbohydrates and amino acids, indicated that both the endophytic system and the aerial shoots of dwarf mistletoes are capable of accumulating large amounts of both carbohydrates and amino acids from their hosts thus, creating a source sink relationship with the host being the source and the dwarf mistletoe acting as the sink. Since cytokinins are potent inducers of nutrient mobilization (Mothes and Engelbrecht 1961; Sequira 1973) Increased cytokinin content in dwarf mistletoes may act as a mechanism for the translocation of host metabolites to the sites of infection. A number of other workers have shown increased cytokinin activity in tissues of obligate fungal parasites and their infected host tissue (Kiraly et. al 1967; Kirhuizen and Staples 1968; Thimann and Sachs 1966).

Localized infections of Arceuthobium, such as A. tsugense on western hemlock, are characterized by a fusiform swelling which usually indicates the extent of the endophytic system (Scharpf 1962). Such swe11ings result from stinulated cambial activity in the infected region of 
the host stem. Because of the well known effects of cytokinins on cell division, the increased cytokinin activity observed in infected western hemlock stem tissue could account for the swellings observed in infected tissue. Studies on organisms capable of causing tumors, galls and other manifestations of disorganized growth in a wide variety of plant species, have demonstrated there is indeed, increased cytokinin activity associated with a wide variety of these pathogens (Phillips and Torrey 1970; Phillips and Torrey 1972; Upper et. a1. 1970; Sequeira 1973; Syono and Torrey 1976; Peterson and Miller 1976; Edwards and LaMotte 1975; Lalowe et. al. 1977; Tegley et. a1. 1971; Henson and Wheeler 1977). In a number of cases, where the pathogens could be isolated and grown in culture, it was shown that the organisms themselves had the ability to produce cytokinins and excrete them into the culture media (Barthe and Bulard 1974; Tegley et. al. 1971; Miller 1975; Burrows 1976). In the case of obligate parasites, such as dwarf mistletoes, it is obvious that the determination of a possible role of cytokinins is considerably more complicated because the parasite cannot be grown separately from the host. Perhaps, the most difficult topic to address is that of the altered growth pattern (formation of "witches' brooms") that is observed in dwarf mistletoe infected hosts. Cytokinins have been implicated in this process in other species where "brooming" is observed in response to pathogens (Hill 1973; Barthe and Bulard 1974). Barthe and Bulard (1974) were able to culture the fungus Taphrina cerasi, which causes "witches brooms" in a number of hosts, in liquid media and demonstrated the presence of zeatin in the culture media. 
In this study, I have demonstrated that increased cytokinin activity occurs in the Spring just prior to bud break. Also, as pointed out previously, there are differences in the cytokinin makeup between

- infected and uninfected hosts and the aerial shoots. The patter of Spring increases holds for all of the material tested and is not unexpected since it is during this time period when most cell division takes place in the newly developing buds and most growth patterns are determined. In western hemlock the increased cytokinin activity in the area of the infection could account for the "broom" formation by releasing the lateral buds from apical control and thus allowing a greater number of lateral branches to grow in this region.

In Douglas-fir the situation is undoubtedly more complicated because of the systemic nature of the infection. The decreased levels of activity and the lack of zeatin in the first growth segment, which includes the terminal bud, are somewhat puzzling and seemingly fail to explain the earlier than normal bud break seen in infected trees. However, it can be pointed out that it is difficult to make direct comparisons between the infected and the uninfected material since the terminal bud size and the number of lateral buds is different. It must also be remembered that although there is greater cytokinin activity in the uninfected first growth segment, the timing of this upswing in the activity is critical in establishing growth patterns and the increase in cytokinin activity in the infected material is three weeks prior to that in the uninfected sample.

This earlier than normal bud break could be advantageous to the parasite since it might allow access to stored nutrients at a time when 
they are still unavailable to the healthy tissues. Tromp (1970) has suggested that endogenous cytckinins may have a role in mobilizing stored proteins. Finally, and perhaps most importantly, the role of other growth regulators, especially the gibberellins and abscisic acid which are important factors in controlling dormancy, must be evaluated before any final conclusions can be made.

The finding of increased cytokinin activity and chemical species in the fifth growth segment of infected Douglas-fir lends some support to cytokinin involvement in "broom" formation in that this increased activity proximal to the terminal bud could account for the release of lateral buds from apical suppression due to the basipetal transport of auxins. (Since this study looked at only the first and fifth growth segments of the terminal branches, it is difficult to say this for certain). Exogenously applied cytokinins are capable of releasing lateral buds from apical control (Thimann and Sachs 1966; Steward and Krikorian 1971) and in other diseases where alteral bud release is observed, increased cytokinin activity has been noted (Thimann and Sachs 1966; Barthe and Bulard 1974).

The increased cytokinin activity found in the aerial shoots of the dwarf mistletoes probably is not important in the formation of "witches' brooms" since it is highly unlikely that they are transported to the lateral buds of the host. It is generally accepted that most cytokinins are synthesized in the roots and moved through the xylem to specific sites (Steward and Krikorian 1971; Leopold and Kriedmann 1975) although, more recent evidence indicates that some cytokinins may be synthesized 
in actively growing buds (Tucker 1977). Neither of these hypotheses would lead to the eoñclusion that increased cytokinin activity in the aerial shoots could influence the release of lateral buds.

Since this study looked at only the first and fifth growth segments of the terminal branches, it is difficult to state an exact mechanism of "broom" formation. In my opinion it is necessary to conduct further studies which would look at cytokinin activity and content proximal to the infection site where there are greater numbers of lateral branches released from apical control.

Because the major symptom of "witches' broom" formation seems to be the abnormal outgrowth of lateral buds and the inception of cell division in previously non-dividing cells, it is logical to assume some involvement of cytokinins since these phenomina are two of the major responses elicited by these hormones. However, as emphasized in the introduction, it is important to keep in mind that in situations where complex developmental processes are taking place it is dangerous to assume any single factor as the sole agent responsible. In intact plant systems plant growth regulators rarely, if ever, function alone. There are many antagonistic and synergistic reactions already identified among the already discovered plant hormones and the list is expanding rapidly as more of these substances are discovered. Although there is clearly a relationship between cytokinin levels and dwarf mistletoe infection, their role remains undiscovered. Further studies are needed to elucidate the temporal interaction of cytokinins with other hormones and to determine their source, site, and mode of action, before any real understanding is possible of 
the complex metabolic events which control early bud break, broom formation, delayed senescence and the establishment of nutrient sinks. 
REFERENCES

Alvim, R., E.W. Hewett and P.F. Saunders. 1976. Seasonal variation in the hormone content of willow. I. Changes in abscisic acid content and cytokinin activity in the xylem sap. Plant Physiol. 57: 474-476.

Barthe, P. and C. Bulard. 1974. Identification d'une cytokinine par chromatographie en phase gazeuse a partir de cultrues pures de taphrina cerasi. Can. J. Bot. 52: 1515-1518.

Biddington, N.L. and T.H. Thomas. 1973. A modified Amaranthus betacyanin bioassay for the rapid determination of cytokinins in plant extracts. Planta 111: 183-186.

Bidwell, R.G.S. 1974. Plant Physiology. p. 548. Maçmillan Publishing Co., Inc. New York.

Burrows, W.J. 1976. Mode of action of N,N-Diphenylurea: The isolation and identification of the cytokinins in the transfer RNA from tobacco callus grown in the presence of $N,[-1)$ iphenylurea. Planta $\$ 30$ : 313-316. .

Carison, W.C. and M.M. Larson. 1977. Changes in auxin and cytokinin activity in roots of red oak, Quercus rubra, seedlings during lateral root formation. Physiol. Plant. 41: 162-166.

Challice, J.S. 1977. Inhibition by phenolic compounds of cytokininstimulated betacyanin synthesis in Amaranthus caudatus. Biologia Plantarum 19: 212-218.

Childs, T.W. and K. Shea. 1967. Annual losses from disease in Pacific Northwest Forests. USDA Forest Service Bulletin PNW-20. 19p.

Daly, J.M. and H.W. Knoche. 1976. Hormonal involvement in metabolism of host-parasite interactions. Pp. 117-133 in J. Friend and D.R. Threlfall, eds., Biochemical Aspects of Plant-Parasite Relationships. Academic Press, San Francisco.

Davey, J.E. and J. VanStaden. 1977. A cytokinin complex in the developing frutts of Lupinus albus. Physiol. Plant. 39: 221-224.

Dimalla, G.G., J. VanStaden and A.R. Smith. 1977. A comparison of the endogenous hormone levels in stolons and sprouts of the potato Solanum tuberosum. Physiol. Plant. 41: 167-171. 
Edwards, W.J. and C.E. LaMotte. 1975. Evidence for cytokinins in bacterial leaf nolules of Psychotria punctata (Rubiaceae). Plant Physiol. 56: 425-428.

Fletcher, R.A. and D. McCullagh. 1971. Cytokinin-induced chlorophyll formation in cucumber cotyledons. Planta 101: 88-90.

Graham, D.P. 1961. Dwarf mistletoe of Douglas-fir. USDA Forest Service Pest Leaflet 54. 4p.

Greenham, C.0. and D.A. Leonard. 1965. The amino acids of some mistletoes and their hosts. Amer. J. Bot. 52: 41-47.

Haglund, S.A. and O.J. Dooling. 1972. Observations on the impact of dwarf mistletoe on Douglas-fir in western Montana. USDA Forest Service Northern Region, Insect and Disease Report No. D-72-1. $6 \mathrm{p}$.

Hawksworth, F.G. and D. Wiens. 1972. Biology and classification of dwarf mistletoes (Arceuthobium). 1972. USDA Forest Service Agricultural Handbook No. 401. 234 p.

Henson, I.E. and C.T. Wheeler. 1977. Hormones in plants bearing nitrogen fixing root nodules: Distribution and seasonal changes in level of cytokinins in Alnus glutinosa (L.) Gaertn. J. Expt. Bot. 28: 205-214.

Hewett, E.W. and P.F. Wareing. 1973. Cytokinins in Populus X robusta: Changes during chilling and bud burst. Physiol. Plant. 28: 393-399.

Hill, T.A. 1973. Endogenous Plant Growth Substances. Edward Arnold Limited, London.

Hull, R.J. and D.A. Leonard. 1964a. Physiological aspects of parasitism in mistletoes (Arceuthobium and Phoradendron). I. The carbohydrate nutrition of mistletoe. Plant Physiol. 39: 9961007 .

Hull, R.J. and D.A. Leonard. 1964b. Physiological aspects of parasitism in mistletoes (Arceuthobium and Phoradendron). II. The carbohydrate nutrition of mistletoe. Plant Physiol. 39: 10081017.

Kiraly, Z., M. El Hammady and B.I. Pozsar. 1967. Increased cytokinin activity of rust (Uromyces phaseoli) - infected bean (Phaseolus vulgaris) and broad bean (Vicia taba) leaves. Phytopathology 57: $93-94$. 
Kirhuizen, H.M. and R.C. Staples. 1968. Mobilization factors in uredospores and bean leaves infected with bean rust fungus. Contrib. Boyce Thompson Inst. 24: 39-52.

Klebe, J.F., H. Finkbeiner, and D.M. White. 1966. Silylations with bis (trimethylsilyl) acetamide, a highly reactive silyl-donor. J. Amer. Chem., 88: 3390-3395.

Kuijt, J. 1960. Morphological aspects of parasitism in dwarf mistletoes (arceuthobium). Univ. of Calif. Pub. in Bot. 30: 337-436.

Laloue, M., C. Terrine and J. Guern. 1977. Cytokinins: Metabolism and biological activity of $\mathrm{N}^{6}-(2-$ isopenteny 1$)$ adenine in tobaco cells and callus. Plant Physiol. 59: 478-483.

Leonard, O.A. and R.J. Hu11. 1965. Translocation relationships in and between mistletoes and their hosts. Hilgardia 37: 115-153.

Leopold, C.A. and P.E. Kriedmann. 1975. Plant Growth and Development. McGraw-Hill Book Company. San Francisco.

Letham, D.J., J.S. Shannon and I.R. McDonald. 1964. The structure of zeatin, a factor inducing cell division. Proc. Chem. Soc., 230-231.

Lightle, P.C. and M.J. Weiss. 1974. USDA Forest Service Pest Leaflet. 19. $8 \mathrm{p}$.

Miller, C.O., F. Skoog, C.S. Okumura, M.H. von Saltza and F.M. Strong. 1955. Structure and synthesis of kinetin. J. Am. Chem. Soc., 77: $2662-2663$.

Miller, C.0. 1975. Revised methods for purification of ribosy1-trans zeatin from Vinca rosa $L$. crown gall tumour tissue. Plant Physiol. 55: 448-449.

Miller, J.R. and R.D. Tocher. 1975. Photosynthesis and respiration of Arceuthobium tsugense (1oranthaceae). Amer. J. Bot. 62: 765-769.

Most, B.J., J.C. Williams and K.J. Parker. 1968. Gas chromatography of cytokinins. J. Chromatog. 38: 130-138.

Mothes, K. and L. Engelbrecht. 1961. Kinetin induced directed transport in excised leaves in the dark. Phytochemistry 1: 58-62.

Peterson, J.B. and C.O. Miller. 1976. Cytokinins in Vinca rosa L. crown gall tumour tissue as influenced by compounds containing reduced nitrogen. Plant Physiol. 57: 393-399.

Phillips, D.A. and J.G. Torrey. 1970. Cytokinin production by Rhizobium japonicum. Physiol. Plant. 23: 1075-1083. 
Phillips, D.A. and J.G. Torrey. 1972. Studies on cytokinin production by Rhizobium. Plant Physiol. 49: 11-15.

Scharpf, R.F. 1962. Growth rate of the endophytic system of dwarf mistletoe on digger pine. Pacific Southwest Forest and Range Expt. Sta. Res. Note 193. 5p.

Scharpf, R.F. and F.G. Hawksworth. 1968. Dwarf mistletoe on sugar pine. USDA Forest Service Pest Leaflet 113. 4p.

Sequeira, L. 1973. Hormone metabolism in diseased plants. Annu. Rev. Plant Physiol. 24: 353-380.

Shea, K.R. 1966. Dwarf mistletoe on coastal western hemlock: principles and practices for control. Weyerhauser Forestery Paper No. 9. Weyerhauser Forestry Research Center, Centralia, Washington. 9p.

Shea, K.R. and B. Howard. 1969. Dwarf mistletoe control: a program for research and development in the west. Forest Pest Conditions (S.F., California, 1968). Proc. pp. 25-32. West Forest and Conserv. Assc., Portland, Ore.

Shea, K.R. and J.L. Stewart. 1972. Hemlock dwarf mistletoe. USDA Forest Service Pest Leaflet 135. 6p.

Shindy, W.W. and O.E. Smith. 1975. Identification of plant hormones from cotton ovules. Plant Physiol. 55: 550-554.

Skoog, F. and D.J. Armstrong. 1970. Cytokinins. Annu. Rev. Plant . Physiol. 21: 359-384.

Smith, R.B. 1969. Assessing dwarf mistletoe on western hemlock. For. Sci. 15: 277-286.

Steward, F.C. and A. Krikorian. 1971. Plants, Chemicals and Growth. Academic Press, New York.

Stewart, J.I. and K.R. Shea. 1971. Forest diseases of the Pacific Northwest. USDA Forest Service Pacific Northwest Forest and Range Exp. Sta. 14p.

Syono, K. and J.G. Torrey. 1976. Identification of cytokinins of root nodules of the garden pea, Pisum sativum L. Plant Physiol. 57: 602-606.

Tegley, J.R., F.H. Whitman and M. Krasnuk. 1971. Chromatographic analysis of a cytokinin from tissue cultures of crown-gall. Plant Physiol. 47: 581-585. 
Thimann, K.V. and T. Sachs. 1966. The role of cytokinins in "fasciation" disease caused by Corynebacterium fascians. Amer. J. Bot. 53: 731-739.

Thomas, T.H., J.E. Carroll, F.M.R. Isenberg, A. Pendegrass, and L. Howell. 1975. A simple, inexpensive, high pressure liquid chromatographic method for separating cytokinins in plant extracts. Plant Physiol. 56: $410-414$.

Tromp, J. 1970. Storage and mobilization of nitrogenous compounds in apple trees with special reference to arginine. Pp. 143-159 in L.C. Luckwill and C.V. Cutting, eds., Physiology of Tree Crops. Academic Press, London and New York.

Tucker, D.J. 1977. Hormonal regulation of lateral bud outgrowth in the tomato. Plant Science Letters. 8: 105-111.

Upper, C.D., J.P. Helgeson, J.D. Kemp and C.J. Schmidt. 1970. Gas liquid chromatographic isolation of cytokinins from natural sources. 6- (3methy 1-2-butenylamine) purine from Agrobacterium tumafasciens. Plant Physiol. 45: 543-547.

VanStaden, J. 1976. Seasonal changes in the cytokinin content of the Ginkgo biloba leaves. Physiol. Plant 38: 1-5.

VanStaden, J. 1977. Seasonal changes in the cytokinin content of the leaves of Salix babylonica. Physiol. Plant. 40: 296-299.

Varner, J.E. and D.T.H. Ho. 1977. Hormones. Pp. 713-770 in J. Bonner and J.E. Varner, eds., Plant Biochemistry. Academic Press, San Francisco. 
APPENDIX I

LIST OF ABBREVIATIONS

DFSp 1H Douglas-fir Spring lst growth segment - healthy

DFSp 5H Douglas-fir Spring 5th growth segment - healthy

DFSp $11 \quad$ Douglas-fir Spring lst growth segment - infected

DFSP $5 I \quad$ Douglas-fir Spring 5 th growth segment - infected

DFSp AS Douglas-fir Spring aerial shoots

DFS 1H Douglas-fir Summer lst growth segment - healthy

DFS 5H Douglas-fir Sumer 5th growth segment - healthy

DFS 1 I Douglas-fir Summer 1st growth segment - infected

DFS $5 I \quad$ Doulgas-fir Summer 5 th growth segment - infected

DFS AS Douglas-fir Summer aerial shoots

DFF 1H Douglas-fir Fall lst growth segment - healthy

DFF $5 \mathrm{H} \quad$ Doulgas-fir Fall 5 th growth segment - healthy

DFF $1 I$ Douglas-fir Fall lst growth segment - infected

DFF $5 I \quad$ Douglas-fir Fall 5th growth segment - infected

DFF AS Douglas-fir Fall aerial shoots

DFW 1H Douglas-fir Winter lst growth segment - healthy

DFW 5H Douglas-fir Winter 5 th growth segment - healthy

DFW II Douglas-fir Winter lst growth segment - infected

DFW 5I Douglas-fir Winter 5th growth segment - infected

DFW AS Douglas-fir Winter aerial shoots

WHSp H Western hemlock Spring tissue - healthy

WHSp I Western hemlock Spring tissue - infected 


$\begin{array}{ll}\text { WHSp AS } & \text { Western hemlock Spring aerial shoots } \\ \text { WHSH } & \text { Western hemlock Summer tissue - healthy } \\ \text { WHS I } & \text { Western hemlock Summer tissue - infected } \\ \text { WHS AS } & \text { Western hemlock Summer aerial shoots } \\ \text { WHF H } & \text { Western hemlock Fall tissue - healthy } \\ \text { WHF I } & \text { Western hemlock Fall tissue - infected } \\ \text { WHF AS } & \text { Western hemlock Fall aerial shoots } \\ \text { WHW H } & \text { Western hemlock Winter tissue - healthy } \\ \text { WHW I } & \text { Western hemlock Winter tissue - infected } \\ \text { WHW AS } & \text { Western hemlock Winter aerial shoots }\end{array}$

